\title{
Optimising Renewable Energy Integration in New Housing Developments with Low Carbon Technologies
}

\author{
Gemma Oliver Gil a , Jahedul Islam Chowdhury ${ }^{a^{*}}$, Nazmiye Balta-Ozkan ${ }^{\text {a }}$, Yukun Hu ${ }^{\text {b }}$, Liz Varga ${ }^{\text {b }}$ \\ and Phil Hart ${ }^{\mathrm{a}}$ \\ ${ }^{a}$ School of Water, Energy and Environment, Cranfield University, Bedford MK43 0AL, UK \\ ${ }^{\mathrm{b}}$ Department of Civil, Environmental and Geomatic Engineering, University College London, London \\ WC1E 6BT, UK
}

\begin{abstract}
Since buildings account for more than one-third of final energy use, it is important to integrate renewable energy sources for new housing developments to reduce demand for grid energy and carbon emissions. This research investigates the potential of solar PV, energy storage, and electric vehicles in new housing developments and their associated grid impacts by taking the UK's Cambridge, Milton Keynes, Oxford arc as a case study. Using published data on electrical loads for different types of dwellings, energy demands for new housing developments with and without renewable and low carbon technologies are analysed using techno-economic modelling frameworks. Technical analysis includes sizing and optimisation of PV and storage while economic analysis covers cost-benefit analyses, by considering a range of existing and future tariffs and subsidy schemes including Standard, Economy 7 (cheaper electricity for seven hours at night), Feed-in tariff, and the Smart Export Guarantee. Results show that installing PV panels and storage systems not only reduces the dwellings' grid energy demand by $31 \%$ in January but also helps the dwellings to become net exporters of green electricity to the grid in July and hence saves a substantial amount of money by taking advantage of Feed-in and Economy 7 tariffs.
\end{abstract}

Keywords: New housing developments, Solar PV, Renewable energy sources (RES), Electric vehicles (EVs), Battery storage, Grid impacts

\section{Introduction}

Globally, buildings are responsible for more than $30 \%$ of final energy consumption and greenhouse gas (GHG) emissions [1,2]. In particular, domestic and commercial buildings are the biggest energy consumers (43\% of total consumption), subsequently accounting for a large share of GHG emissions in the UK [3]. Following the advice from the Committee on Climate Change, the UK government has decided to take a further step than the Climate Change Act [4] to bring all greenhouse gas emissions to net-zero by 2050. With the approval from the Parliament, Climate Change Act 2008 (2050 Target Amendment) Order 2019 came into force on 27 June 2019 which translates into a target for a $100 \%$ reduction of greenhouse gas emissions (compared to 1990 levels) in the UK by 2050 [5]. This ambitious target will require radical changes in the ways energy is generated, delivered and used by all sectors including the housing sector. It is believed that buildings have a large potential for energy efficiency gains and thus, their energy consumption can be reduced [6]. This raises the opportunity for energyefficient design of new housing developments from the start. Any new housing developments have a 
huge impact on the environment, society and economy, and hence planning for sustainable development benefits all these three aspects [7].

To make urban areas pollution-free and comfortable, planning should integrate electrical mobility. Since the transport sector makes a large contribution to GHG emissions (27\% of the total GHG emission in the UK [8]), electric vehicles (EVs) are expected to make a significant contribution toward the decarbonisation of the transport sector. According to the UK government's report "The Road to Zero" [9], new homes built in the UK need to be fitted with an EV charging point. This requirement is further supported by the study "Future Energy Scenarios (FES)" carried out by the National Grid, which predicted that $90 \%$ of vehicles sold in the UK by 2050 will be EVs [10]. It is thus expected that new dwellings in the UK will be equipped with EV charging points. These charging points if connected with EVs will have a significant impact on grids via increase of the dwellings' loads. Even though off-peak charging options might reduce grid impacts, as suggested by Paevere et al. [11], each dwelling with an EV will still increase the demand for grid energy. Although grid energy itself is undergoing a programme of decarbonisation[12], the adoption of energy-efficient and low carbon power generation technologies at the dwelling level can make significant contributions.

Although energy-saving technologies can be adopted at any phase of the life-cycle of a building (for instance retrofitting a building with better thermal insulation or adopting heat pumps for space heating), the most significant impact is made in the design and construction phase of dwellings [7]. The design parameters of buildings such as energy performance, building construction typology, type of neighbourhood and density can reduce energy consumption and hence environmental impacts significantly [13-16]. A further reduction of environmental impacts of the building sector is possible by adopting extensive use of renewable energy sources. Renewable energy can be produced on-site or nearby housing developments. A proper mix of renewable energy, electrical transportation and grid design are key parameters for sustainable urban development [17]. Sustainable buildings commonly use renewable sources such as passive solar home design, photovoltaic (PV) technologies, solar thermal systems, green roofs or rain gardens [7]. The use of solar PVs as a renewable energy source has increased significantly over past decades in worldwide new building construction [18] but since solar radiation fluctuates during the day there are times when the generation from PV exceeds demand. To take the maximum advantage of PV surplus and smooth supply characteristics, solar energy may be stored in batteries. Although solar PV is the key technology to develop an optimal energy system design for homes, storage technology is also important to maximise the system's benefits [19].

It is evident from the literature that both high energy efficiency and renewable energy generation for buildings are essential to achieve the concept of the "Zero Energy Building (ZEB)"[2]. The ZEB is a term used to define a building's performance that is high in energy efficiency and its required energy entirely comes from renewable sources. Several recent articles emphasize that the prospect of ZEB can be realised only by shifting the boundary of carbon performance from a single building to the neighbourhood level, thereby sharing infrastructures and resources [13,20,21]. Although many scholars have studied the impact of urban form and neighbourhoods (e.g. suburban vs rural living,) on energy consumption and carbon emissions [22-24], they focused on existing cities, and hence the knowledge is diffuse and sectoral, and considers buildings and transports in isolation [25]. The increase of EVs' uptake across the world and the potential for charging the vehicles at homes raise the opportunity to 
integrate transports and buildings. This integration along with on-site electricity generation from renewable sources can reduce grid dependency and help decarbonisation of housing and transport sectors.

To further accelerate the decarbonisation, incentives are offered to dwellers to encourage the uptake of renewable energy technologies for heat and electricity generation via schemes such as Renewable Heat Incentives (RHI) [26] and Feed-in tariffs [27]. However, the techno-economic aspects of energy demand growth due to new housing sites with and without the adoption of renewable and low carbon technologies are poorly understood [28]. Therefore, this research aims to address this gap by investigating the impact of new housing developments on energy infrastructures and assesses the potential of renewable and low carbon technologies, mainly solar PV with storage and EVs, to manage electricity demand. This paper also evaluates the economic prospects of using PV and storage by taking advantage of current and potential future tariffs to identify which option is economically viable for prosumers in large housing sites.

The rest of the paper is organised as follows: Section 2 describes the methodology of this study including PV and storage sizing for different types of dwellings, economic modelling and data sources for this research. Section 3 provides results of energy demand reduction potential with and without low carbon technologies, cost-benefit of proposed options, and grid impact savings. Section 4 presents a comprehensive discussion for energy generation and demand management of new housing developments and the impacts on the grid as well as broader implications. Section 5 provides conclusions and recommendations for future work.

\section{Methodology}

We investigated new housing developments in Central Bedfordshire, which is one of the counties of the Cambridge-Milton Keynes-Oxford (CaMKOx) arc in the UK, as a case study that can be extrapolated to the whole arc and other areas around the world. The CaMKOx arc is a set of cities and towns around 50-miles radius of London (see Fig. 1), which is one of the fastest-growing regions of the UK with an expected increase in its population of 1.9 million and 335,000 new jobs by 2050 [28]. The creation of new housing developments, services and new infrastructure to connect the CaMKOx cities are seen essential for the growth of the arc. With world-class universities, research locations and high-tech firms, the arc's future economic growth is threatened by the absence of affordable housing and appropriate connective infrastructures. Therefore, the National Infrastructure Commission (NIC) proposes the construction of 30,000 new homes per year until 2050 to accommodate the people and secure the arc's long term economic success [28]. 


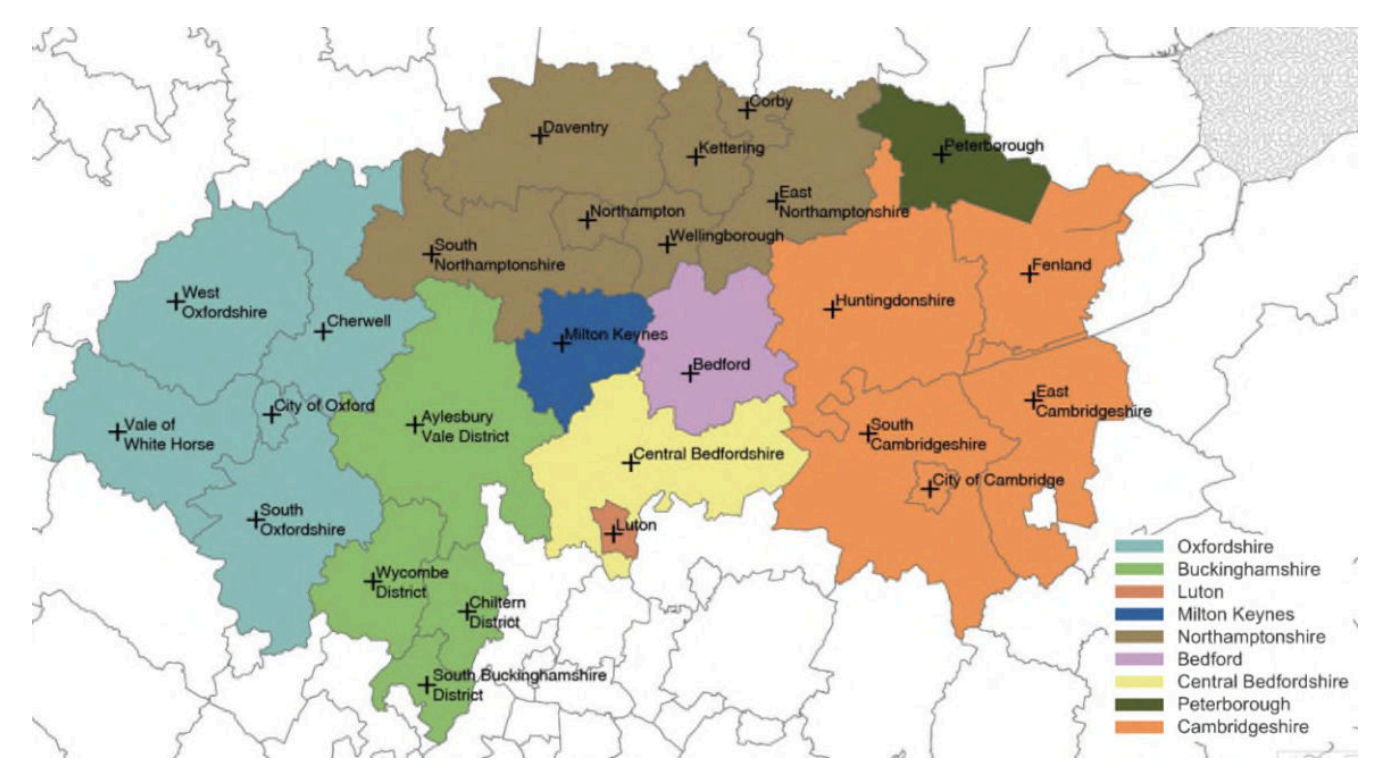

Fig. 1. Map of existing local government bodies across Cambridge-Milton Keynes-Oxford arc [28].

It was assumed that every new dwelling in the arc would be connected to the grid and they would have solar PV arrays, battery storage, and an EV (see Fig. 2). Firstly, baseline energy demand for new housing developments in the selected area was calculated by adding potential EV charging patterns to dwellings' electricity demand. The heating load, however, was not included here due to the fact that, currently, most (over 80\%) of the domestic heating demand in the UK is met by gas boilers [29]. More recently, the UK Government has announced that fossil fuel based boilers (oil and natural gas fired) will be banned from new housing built after 2025 [30]. There are many alternatives that are discussed as a potential replacement for fossil fuel boilers including heat pumps and hydrogen based heating [31], storage heaters [32], biomass fired district heating [33], and industrial waste heat via district heat network [34]. However, it is not clear which alternative heating options will be best suited that is a low cost, low carbon and providing best services people need, for new houses against an anticipated new Future Home Standard (FHS) [35], which is yet to be introduced by the UK Government. In this research, we assumed that the heating demand of new houses in the near future will potentially be supplied by hydrogen based on-site boilers/fuel cells or biomass and industrial waste heat based district heat network. As a result, we focused only on electricity demand for houses in new housing developments. The baseline electricity demand was assumed to be supplied by the grid. These demands are to be compared with alternative scenarios such as a) energy supplied from rooftop's solar PV and storage and b) energy from option (a) plus load shifting with storage. To maximise the financial benefits and reduce grid congestion, it was assumed that batteries stored cheap electricity from the grid during the night for use in the day in option (b). The detail methodology of this research is shown in Fig. 3. In the economic analysis, the baseline scenario with standard electricity tariff was compared with alternative scenarios with Economy 7 and Feed-in-Tariffs (FIT). Economy 7 is a tariff that offers customers cheaper electricity for 7 hours during the night. FITs are a renewable energy incentive whereby dwellings are eligible to receive payments on the installation of PV panels. 


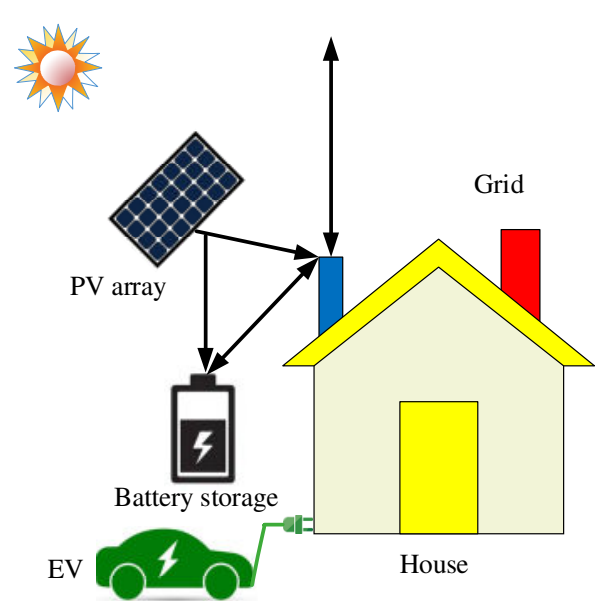

Fig. 2. All houses in the study are assumed to have solar PV arrays, battery storage, and an EV

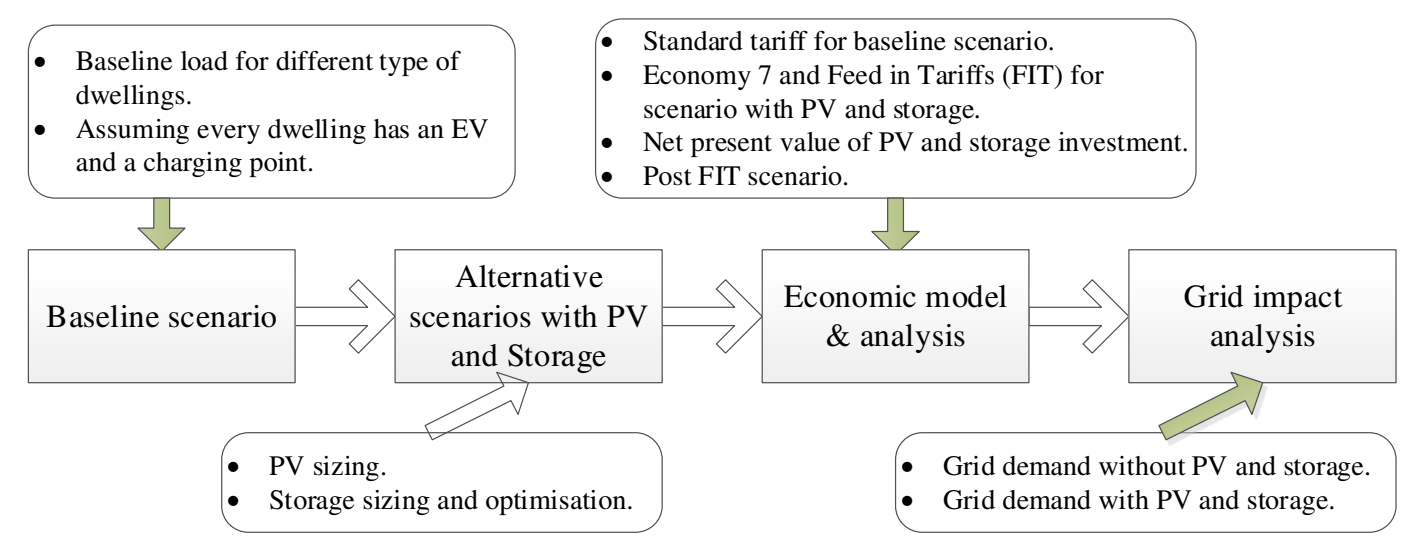

Fig. 3. Flow chart of research methodology

\subsection{Baseline scenario models}

Given the need for electrification of transport to decarbonise the energy system, it is necessary to install an EV charging point for each new home that owns an EV. It was assumed that every new dwelling along the arc would own an EV. Therefore, the baseline load of each dwelling is given by

$W_{\text {base }}=B L_{\text {dewl }}+\tau \times C$

where $W_{\text {base }}$ is the baseline load in $\mathrm{kWh}, B L_{\text {dewl }}$ is the baseload for each dwelling type in $\mathrm{kWh}, \tau$ is the charging time in hours and $C$ is the capacity of EV charger in $\mathrm{kW}$.

EV charging time can be calculated as follows:

$$
\tau=\frac{\mathrm{D}}{L * C}
$$

where $\mathrm{D}$ is the number of miles per day that an $\mathrm{EV}$ is expected to travel, $L$ is travel capacity of an EV per $\mathrm{kWh}$ of charge (miles/kWh).

Depending on the size, model and autonomy of EVs, the capacity of the battery varies. Small cars like Smart Fortwo or BMW i3 have batteries of 16.5 and $22 \mathrm{kWh}$, respectively, while medium-sized cars 
such as Nissan Leaf hold a $40 \mathrm{kWh}$-battery, and bigger cars like Tesla S are equipped with $100 \mathrm{kWh}$ batteries. For this study, Nissan Leaf was chosen to develop all the scenarios because it was the most commonly bought EV in the UK during the first quarter of 2018 [36]. It was assumed that there is no necessity to fully charge the battery every day since the average commuting trip in England is around 10.9 miles while shopping and leisure trips are 4 and 8.6 miles, respectively [37]. On this basis, it was considered that on average a car runs 30 miles a day, which includes commuting and other short-distance trips. This study also assumed that every home was equipped with a $7 \mathrm{~kW}$ charger, which will become a standard among dwellings in 2050 [10].

Drivers in the UK charge EVs, using mostly grid electricity, at different locations and various times of a day. The majority, around 80\% [38], of all electric car charging happens at home with around 35\% charging typically between 17:00 $\mathrm{h}$ and 20:00 $\mathrm{h}$ [39]. Hence, in the baseline scenario, it was assumed that most people do not charge the EV at work, but they charge it just when arriving home. Based on average commuting distance, office hours and travelling times, it was supposed that people plug-in EVs to charge at 18:00 h. This assumption was made for two reasons: firstly, to estimate the maximum possible peak demand of grid electricity by a dwelling when an EV is charged in the baseline scenario, which, in practice, can be charged any time of a day and secondly, to allow owners to charge their EVs from solar PV and storage in alternative scenarios as it is expected that every home in the arc would have solar electricity.

\subsection{Alternative scenarios with solar PV and storage}

To select the right size of a PV system that includes solar PV array and battery storage, ideally, it is necessary to know the dwellings' energy demand pattern throughout a day. The specification of the PV module used for this study is shown in Table 1. Based on the required load to be supplied by solar energy the number of PV modules can be increased. However, the maximum number of PV panels is to be restricted by the suitable rooftop area of dwellings that could hold PV panels. For example, in the UK, a typical average detached house has a suitable roof area of $29.5 \mathrm{~m}^{2}$, a modern mid or end terrace has $18 \mathrm{~m}^{2}$, and an average semi-detached has $20 \mathrm{~m}^{2}$ [40]. The suitable roof space for PV installation in Flats, however, vary depending on the type and number of flats in a building. For example a purpose-built two bedroom flat in a two storey building may have $14 \mathrm{~m}^{2}$ for PV installation [40]. Nonetheless, in case of low and high-rise buildings, the suitable roof area for each flat could be much lower than a purposely built flat. In modern time, multi-story buildings could be designed in a way that can provide sufficient spaces for PV installation on the roof, facades and shades [41,42]. In this research, we assumed that the flats are all in low rise buildings and that buildings have sufficient spaces to hold enough PV panels that could meet electricity demand for flats.

The PV array size for each type of dwelling was calculated in two ways: considering the annual and the daily electricity consumption profiles. Results of both profiles were compared, and the best methodology for sizing the array was determined to be the one that took the most advantage of solar radiation and had a lower installation cost, which involved a lower investment cost. 
Table 1. Specification of PV module and installation

\begin{tabular}{lll}
\hline Parameter & Values & \\
\hline PV module & N310K Photovoltaic Module HIT® \\
& BLACK of Panasonic [43]. & \\
Rated power, $w$ & $0.310 \mathrm{kWp}$ & \\
Module efficiency, $\eta_{p v}$ & $18.5 \%$ & \\
Module area, $A_{P V}$ & $1.67 \mathrm{~m}^{2}$ & \\
Module mounting on roof & Fixed & \\
Module orientation (azimuth) & $0^{\circ}$ & \\
Module inclination & $37^{\circ}$ & \\
\hline
\end{tabular}

\subsubsection{Sizing PV array based on annual electricity consumption}

The size and number of PV array can be calculated from the annual electricity output of PV systems and the consumption per dwelling type.

The annual energy output of a single PV is given by

$W_{a}=w \times K_{k} \times S F$

The number of PV for each dwelling type is calculated by

$$
n_{P V, a n}=\frac{W_{d w e l}}{W_{a}}
$$

where $W_{a}$ is the total annual energy output in $\mathrm{kWh}, w$ is the power rating of the PV system in $\mathrm{kWp}$, $K_{k}(\mathrm{kWh} / \mathrm{kWp})$ is a factor considering the location and the orientation of the panels, $S F$ is the shading factor. $W_{d w e l}$ is the annual electricity consumption of a dwelling and $n_{P V, a n}$ is the number of PV panels required by the annual consumption model.

The location of the Central Bedfordshire falls into zone 1 of the UK zonal maps [44]. The potential solar output for zone 1 depending on the orientation and the inclination of the PV array is shown in Table 2. The maximum and minimum outputs are in dark green and dark red, respectively. Assuming that the array was fully orientated to the south (azimuth $0^{\circ}$ ) with an inclination angle of $37^{\circ}$ (fixed mounting), the annual PV outputs per $\mathrm{kWp}$ was $985 \mathrm{kWh} / \mathrm{kWp}$ from Table 2 . The inclination angle chosen was the best angle that provides maximum annual output from PV arrays facing directly south (see Table 2). Since this case study was estimating new housing areas for Central Bedfordshire, the $S F$ value of 1 was considered. 
Table 2. $K_{k}$ table for Central Bedfordshire (zone 1) [44].

\begin{tabular}{|c|c|c|c|c|c|c|c|c|c|c|c|}
\hline \multirow{48}{*}{ 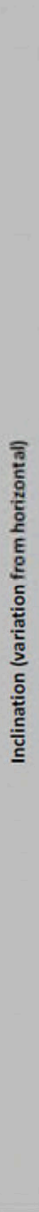 } & & \multicolumn{10}{|c|}{ Orientation (variation from south) } \\
\hline & & 0 & 5 & 10 & 15 & 20 & 25 & 30 & 35 & 40 & 45 \\
\hline & 0 & 828 & 828 & 828 & 828 & 828 & 828 & 828 & 828 & 828 & 828 \\
\hline & 1 & 835 & 835 & 835 & 835 & 835 & 835 & 834 & 834 & 833 & 833 \\
\hline & 2 & 843 & 843 & 843 & 842 & 842 & 841 & 841 & 840 & 839 & 838 \\
\hline & 3 & 850 & 850 & 850 & 849 & 849 & 848 & 847 & 846 & 845 & 843 \\
\hline & 4 & 857 & 857 & 857 & 856 & 855 & 854 & 853 & 852 & 850 & 848 \\
\hline & 5 & 864 & 864 & 864 & 863 & 862 & 861 & 859 & 857 & 855 & 853 \\
\hline & 6 & 871 & 871 & 870 & 869 & 868 & 867 & 865 & 863 & 861 & 858 \\
\hline & 7 & 878 & 877 & 877 & 876 & 874 & 873 & 871 & 868 & 866 & 862 \\
\hline & 8 & 884 & 884 & 883 & 882 & 880 & 879 & 876 & 873 & 870 & 867 \\
\hline & 9 & 890 & 890 & 889 & 888 & 886 & 884 & 882 & 878 & 875 & 871 \\
\hline & 10 & 896 & 896 & 895 & 894 & 892 & 890 & 887 & 883 & 880 & 875 \\
\hline & 11 & 902 & 902 & 901 & 900 & 898 & 895 & 892 & 888 & 884 & 879 \\
\hline & 12 & 908 & 908 & 907 & 905 & 903 & 900 & 897 & 893 & 888 & 883 \\
\hline & 13 & 914 & 913 & 912 & 910 & 908 & 905 & 901 & 897 & 892 & 887 \\
\hline & 14 & 919 & 919 & 917 & 916 & 913 & 910 & 906 & 901 & 896 & 890 \\
\hline & 15 & 924 & 924 & 922 & 920 & 918 & 914 & 910 & 905 & 900 & 894 \\
\hline & 16 & 929 & 929 & 927 & 925 & 922 & 919 & 914 & 909 & 903 & 897 \\
\hline & 17 & 934 & 933 & 932 & 930 & 927 & 923 & 918 & 913 & 907 & 900 \\
\hline & 18 & 938 & 938 & 936 & 934 & 931 & 927 & 922 & 917 & 910 & 903 \\
\hline & 19 & 943 & 942 & 941 & 938 & 935 & 931 & 926 & 920 & 913 & 906 \\
\hline & 20 & 947 & 946 & 945 & 942 & 939 & 935 & 929 & 923 & 916 & 908 \\
\hline & 21 & 951 & 950 & 949 & 946 & 943 & 938 & 933 & 926 & 919 & 911 \\
\hline & 22 & 954 & 954 & 952 & 950 & 946 & 941 & 936 & 929 & 922 & 913 \\
\hline & 23 & 958 & 957 & 956 & 953 & 949 & 944 & 939 & 932 & 924 & 915 \\
\hline & 24 & 961 & 961 & 959 & 956 & 952 & 947 & 941 & 934 & 926 & 917 \\
\hline & 25 & 964 & 964 & 962 & 959 & 955 & 950 & 944 & 937 & 928 & 919 \\
\hline & 26 & 967 & 967 & 965 & 962 & 958 & 953 & 946 & 939 & 930 & 921 \\
\hline & 27 & 970 & 969 & 968 & 965 & 960 & 955 & 948 & 941 & 932 & 922 \\
\hline & 28 & 972 & 972 & 970 & 967 & 962 & 957 & 950 & 942 & 933 & 923 \\
\hline & 29 & 975 & 974 & 972 & 969 & 964 & 959 & 952 & 944 & 935 & 924 \\
\hline & 30 & 977 & 976 & 974 & 971 & 966 & 960 & 953 & 945 & 936 & 925 \\
\hline & 31 & 979 & 978 & 976 & 973 & 968 & 962 & 955 & 946 & 937 & 926 \\
\hline & 32 & 980 & 979 & 977 & 974 & 969 & 963 & 956 & 947 & 937 & 926 \\
\hline & 33 & 982 & 981 & 979 & 975 & 970 & 964 & 957 & 948 & 938 & 927 \\
\hline & 34 & 983 & 982 & 980 & 976 & 971 & 965 & 957 & 948 & 938 & 927 \\
\hline & 35 & 984 & 983 & 981 & 977 & 972 & 966 & 958 & 949 & 938 & 927 \\
\hline & 36 & 984 & 984 & 981 & 978 & 973 & 966 & 958 & 949 & 938 & 927 \\
\hline & 37 & 985 & 984 & 982 & 978 & 973 & 966 & 958 & 949 & 938 & 926 \\
\hline & 38 & 985 & 984 & 982 & 978 & 973 & 966 & 958 & 949 & 938 & 925 \\
\hline & 39 & 985 & 984 & 982 & 978 & 973 & 966 & 958 & 948 & 937 & 925 \\
\hline & 40 & 985 & 984 & 982 & 978 & 973 & 966 & 957 & 947 & 936 & 924 \\
\hline & 41 & 984 & 984 & 981 & 977 & 972 & 965 & 956 & 946 & 935 & 922 \\
\hline & 42 & 984 & 983 & 981 & 977 & 971 & 964 & 955 & 945 & 934 & 921 \\
\hline & 43 & 983 & 982 & 980 & 976 & 970 & 963 & 954 & 944 & 932 & 919 \\
\hline & 44 & 982 & 981 & 979 & 975 & 969 & 962 & 953 & 943 & 931 & 918 \\
\hline & 45 & 980 & 980 & 977 & 973 & 967 & 960 & 951 & 941 & 929 & 916 \\
\hline
\end{tabular}

\subsubsection{Sizing PV array based on daily electricity consumption profile}

In this method, the amount of electricity needed to cover the daily demand was calculated. Fig. 4 shows typical daily solar radiations $\left(\mathrm{W} / \mathrm{m}^{2}\right)$ for different months on a $37^{\circ}$ inclined surface that is facing directly south at Marston Moretaine, England. These data were obtained from European Commission's PV Geographical Information Systems database (PVGIS-SARAH), which recorded solar radiation data in different forms from 2005 to 2016 with a spatial resolution of $0.05^{\circ} \times 0.05^{\circ}$ [45]. The database is valid for solar radiation in Europe, Africa, parts of South America and most of Asia. It should be noted that at Marston Moretaine, there is not much solar radiation variation between the months of April, May, June, July, and August. There is also a similarity between the insolation curves of January, November, and December [45]. The highest and lowest insolation curves for typical UK weather conditions, July and January, in Fig. 4 were considered as representative cases for this study. 


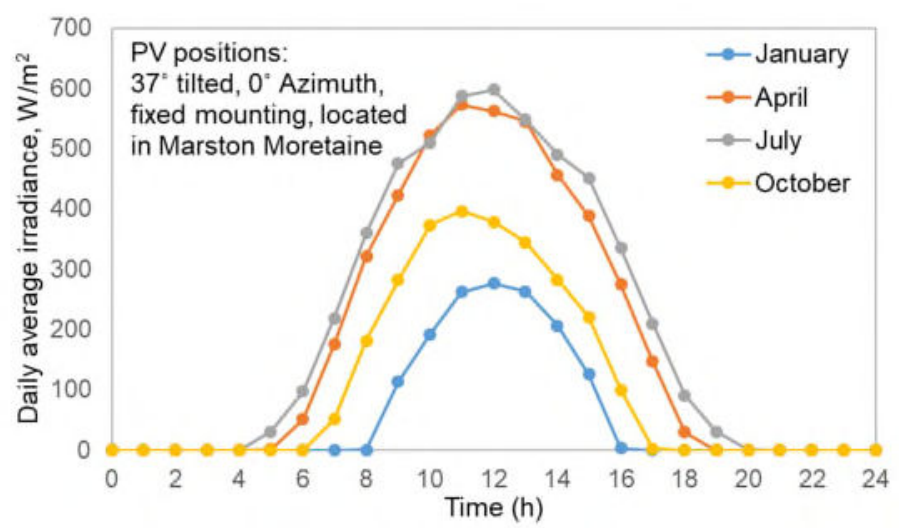

Fig. 4. Average daily solar irradiance for typical weather conditions at Marston Moretaine, UK across different months of a year [45].

The size of the PV array was determined by the day in which there is more generation due to high insolation and less cloudiness, which is a typical July day. So, in the month of July, it was assumed that the daily generation should cover the total demand of the day. Nonetheless, the number of PV panels and their area should not cross the limit of available roof space for holding the PV panels by each dwelling. Hence, the number of PV panels for each dwelling in daily consumption model is calculated by Eq. (5) while PV generation for dwellings in July and January are given in Eqs. (6-7).

$$
\begin{aligned}
& n_{P V, d w e l}=\frac{A_{\text {roof }, d w e l}}{A_{P V}} \\
& W_{J u l y, d}(t)=I_{J u l y, d}(t) \times n_{P V, d w e l} \times A_{P V} \times \eta_{P V} \\
& W_{J a n, d}(t)=I_{J a n, d}(t) \times n_{P V, d w e l} \times A_{P V} \times \eta_{P V}
\end{aligned}
$$

where $I_{J u l y, d}(t)$ and $I_{J a n, d}(t)$ are the actual solar irradiance $\left(\mathrm{kW} / \mathrm{m}^{2}\right)$ on a $37^{\circ}$ inclined surface that is facing directly south under average cloudiness conditions at a given time $t ; W_{J u l y, d}(t)$ and $W_{J a n, d}(t)$ are the electrical power yield $(\mathrm{kW})$ from the PV array, without any losses, at a given time $t ; A_{P V}$ is the area of each PV, $\eta_{P V}$ is the efficiency of a PV system.

In the daily consumption model, dwellings energy demand are expected to be met by PV generation partially or fully depending on the PV size and the type of dwelling. It is also expected that in July there will be more generation than dwelling demand and that any excess demand can be stored in batteries for later use. If there is still excess generation from PV after storing, it can be further exported to the grid. However, in January the opposite is true and more import is needed to fulfil dwelling demand due to lower solar irradiance and daytime hours.

\subsubsection{Sizing of storage}

Several factors influence the overall design of an energy storage system, including the dwelling's required electricity storage capacity, its cost and the battery technology and type. When the PV array is the only source for charging the battery, the output of the solar system should be between the minimum and maximum recommended charge rates by the manufacturer. A typical day in July was taken as a reference for sizing the battery since that is when the highest generation is produced. Based on the 
electricity generation from PV and demand by each dwelling, the excess energy generated by PV was stored in batteries, which is represented by Eq. (8). The maximum size of the battery can be calculated by Eq. (9) which is the summation of the instantaneous storage level of a battery in Eq. (8).

$$
\begin{aligned}
& B S(t)=B S(t-1)+\eta_{B}\left\{W_{j u l y}(t)-D_{d w e l}(t)\right\} \\
& B S_{\text {max }}=\max _{t=0, n}\{B S(t)\}
\end{aligned}
$$

where $B S(t)$ is the amount of energy stored in the battery $(\mathrm{kWh})$ at the end of the current time period $t, B S(t-1)$ is the amount of energy stored in the battery $(\mathrm{kWh})$ at the end of the previous time period $t-1, \eta_{B}$ is the roundtrip efficiency of storage which is assumed to be $95 \%, D_{d w e l, d}(t)$ is the dwelling's electrical load demand $(\mathrm{kW})$ at a given time $t, B S_{\max }$ is the energy storage capacity of the battery (kWh), $n$ denotes the time period occurring at the end of the day, which is considered midnight.

The maximum storage capacity calculated in Eq. (9) may not be the optimal one since the storage energy at this size might not be able to discharge fully every day. This partial discharge from a large battery leads to a low capacity factor, which is defined as the ratio of actual energy supplied to the maximum possible energy that can be supplied over a time period. The low capacity factor is always least attractive from an economic point of view. Thus, the optimal size of the battery in terms of highest capacity factor is more cost effective for the owner, which is calculated in Eq. (10), based on the assumption that the battery would be discharged fully at the end of the day when time $t=n$.

$$
B S_{o p t}=\max _{t=0, n}\{B S(t)\}-B S(n)
$$

where $B S(n)$ is the state of charge of storage at $t=n$, which is calculated in Eq. (8).

There is a wide range of batteries exist for solar PV applications. Lithium-nickel cobalt aluminium oxide (NCA) batteries have a higher energy density, a higher number of lifecycles and need less maintenance than most of the batteries commercially available at this moment [46]. Moreover, the initial investment cost of NCA batteries is further reducing due to an $8-18 \%$ pa decrease of lithium-ion price $[47,48]$. Therefore in this research, NCA batteries were considered.

\subsection{Economic model}

An economic model was developed to compare monthly electricity costs associated with the baseline scenario with standard tariff versus alternative scenarios of PV and storage system with FIT and: (a) Economy 7, (b) Economy 7 and load-shifting with storage, and (c) both (a \& b) but with post-FIT Smart Export Guarantee (SEG) scheme. The FIT and SEG schemes in the UK only incentivise prosumers for PV generation and export. Although FIT and SEG payments are unaffected by using home energy storage, the current schemes do not offer any incentive for installing storage [49]. Therefore, it is expected that without any subsidy for storage, the economic performance of PV and storage for dwellings may not be attractive due to high cost of energy storage. This study thus compares economic propositions of the alternative scenarios with and without a subsidy for storage. The economic model in this research was developed taking advantage of electricity and renewable incentive tariffs in the UK. 
However, the same model can be applied to other countries with different tariffs structure and billing systems.

Electricity price within the standard tariffs in the UK does not differ between day and night, whereas on the Economy 7 tariff electricity consumed during a specified 7 hours of night time is cheaper than during day time (see Table 3). The electricity bills calculated using different tariff structures is given below.

With standard tariff,

$\Omega_{S}=\left(D_{d w e l} \times e_{S}+\alpha_{S}\right) / 100$

With Economy 7 tariff,

$\Omega_{E 7}=\left(D_{d w e l, \text { day }} \times e_{\text {day }}+D_{\text {dwel,night }} \times e_{\text {night }}+\alpha_{E 7}\right) / 100$

where $\Omega_{S}$ and $\Omega_{E 7}$ are the electricity bill with standard and Economy 7 tariffs $(\mathfrak{f})$, respectively; $D_{d w e l}$ is the dwelling electricity consumption $(\mathrm{kWh}), e_{S}$ is the standard tariff $(\mathrm{p} / \mathrm{kWh}), \alpha_{S}$ is the standing charge per day ( $\mathrm{p} /$ day) for standard tariff; $D_{d w e l, \text { day }}$ and $D_{\text {dwel,night }}$ are the dwelling electricity consumption during day and night time $(\mathrm{kWh})$, respectively, $e_{\text {day }}$ and $e_{\text {night }}$ are the daytime and night time tariffs (p/kWh) for Economy 7 tariff, and $\alpha_{E 7}$ is the standing charge per day (p/day) for Economy 7 tariff.

If all (or almost all, depending on the battery size) the electricity needed during the day was purchased the previous night and stored in the battery, e.g. load shifting, the maximum advantage from the Economy 7 could be obtained. The tariff structure in Economy 7 with load shifting option is similar to the Economy 7, except that the storage at night time will be treated as a load for the grid.

Regarding the FIT, dwellings can be eligible to receive payments for generation from PV and export of electricity to the grid. These can be calculated as:

$F I T_{k}=W_{g}\left(\tau_{g}+0.5 \times \tau_{e}\right) / 100$

where $W_{g}$ is the generation of electricity for a dwelling in $\mathrm{kWh}, \tau_{g}$ is the generation tariff $\mathrm{p} / \mathrm{kWh}$, $\tau_{e}$ is the export tariff in $\mathrm{p} / \mathrm{kWh}$.

The generation tariff is the rate that the energy supplier pays to a generator of electricity from solar PV. Once the PV system has been registered, the tariff levels are guaranteed for the period of the tariff (up to 20 years). The export tariff is the rate an energy supplier pays to a generator for $50 \%$ of electricity generated, which is an estimation of the electricity exported to the grid. In April 2019, the UK government closed the FIT scheme for new applicants. However, anyone already in the scheme will continue to receive payments until their contracts end. Also, people or businesses who were certified to take part in the FIT before the cut-off date can still apply for FIT until March 2020 [27]. The UK government is now consulting on introducing a new scheme to replace FIT's export tariff with SEG [50]. Under this new scheme, small-scale low-carbon generators will receive payment for electricity they feed into the grid. The rate is however not finalised yet. In our study, we tested four different cases for the 
SEG tariff relative to the FIT's export tariff: a) same, b) 50\% decreased, c) 50\% increased, and d) $100 \%$ increased. An economic analysis in light of the post-FIT was conducted with these assumptions.

Table 3. Electricity tariffs and payment received from Feed-in and Smart Export Guaranty schemes.

\begin{tabular}{lllll}
\hline & \multicolumn{2}{c}{ Electricity tariffs [51] } & \multicolumn{2}{c}{ Renewable energy payments [52] } \\
\cline { 2 - 5 } & Standard & Economy 7 & FIT* & SEG** \\
\hline Day $(\mathrm{p} / \mathrm{kWh})$ & 14.45 & 15.19 & $\mathrm{n} / \mathrm{a}$ & $\mathrm{n} / \mathrm{a}$ \\
Night $(\mathrm{p} / \mathrm{kWh})$ & 14.45 & 7.67 & $\mathrm{n} / \mathrm{a}$ & $\mathrm{n} / \mathrm{a}$ \\
Standing charge $(\mathrm{p} / \mathrm{day})$ & 30.41 & 32.03 & $\mathrm{n} / \mathrm{a}$ & $\mathrm{n} / \mathrm{a}$ \\
Generation tariff, $(\mathrm{p} / \mathrm{kWh})$ & $\mathrm{n} / \mathrm{a}$ & $\mathrm{n} / \mathrm{a}$ & 3.93 & $\mathrm{n} / \mathrm{a}$ \\
Export tariff for $50 \%$ of electricity, & $\mathrm{n} / \mathrm{a}$ & $\mathrm{n} / \mathrm{a}$ & 5.24 & (a) 5.24, (b) 2.62, \\
(p/kWh) & & & & (c) 7.86, (d) 10.48 \\
\hline
\end{tabular}

*Feed-in tariff rates (in GB pence) for $1^{\text {st }}$ July 2018 to $30^{\text {th }}$ September 2018 for $0-10 \mathrm{~kW}$ solar PV

** SEG tariffs in this research were assumed as the actual tariffs had not been finalised yet.

The cost-effectiveness of the scenarios with PV and storage was estimated by the net present value NPV as follows.

$$
N P V=\frac{R_{t}}{(1+i)^{t}}
$$

where $R_{t}$ is the net cash flow, which is equal to the electricity cost saving minus total investment cost of PV and storage; $i$ is the discount rate which is assumed to be $4 \%$ in this research [53]; $t$ is the time period, fixed in this study to 25 years due to the warranty period of solar PV and storage considered in this research. Total investment cost includes the capital cost of PV and its installation cost and the cost of storage but excludes maintenance costs due to a lesser need for maintenance of the domestic PV system. In case of a battery replacement during the PV lifetime, the cost of the replaced batteries should be added. Furthermore, battery degradation over the lifetime was assumed to be $20 \%$ of the initial capacity and the economic aspect of this loss was also accounted for in the calculation of net cash flow.

\subsection{Data}

\subsubsection{Housing plan data}

The local plan for central Bedfordshire county provides the strategic objectives and vision for the area in the period of 2015 to 2035; objectives consist of creating a minimum of 24,000 new jobs and deliver around 39,350 of new homes [54]. Of these new homes, 23,528 homes were already planned or built. A range of different homes such as detached, semi-detached, flats, etc., to buy and rent was included in the plan. Some of the locations where housing growth was planned include east of Biggleswade, Marston Moretaine, north of Luton, and east of Arlesey. These locations and their proposed number of homes (see Table 4) planned in the housing plan were used in this research. 
Table 4. Number of new homes expected to be built for selected locations in central Bedfordshire [54].

\begin{tabular}{ll}
\hline Location & Number of new homes expected \\
\hline East of Biggleswade & 1500 \\
Marston Moretaine & 5000 \\
North of Luton & 4000 \\
East of Arlesey & 2000 \\
Total & 12500 \\
\hline
\end{tabular}

\subsubsection{Distribution of building types in a new housing development}

In England, the distribution of building types in new housing developments depends on the size of the site. The National House Building Council (NHBC) classifies sites according to the number of new properties: from 1-10, 11-30, 31-100, 101-500 and 501-2000 [55]. Since it is expected that 30,000 new homes per year would be built along the arc [28], the distribution of 101 to 500 dwellings was selected because it is the second biggest in numbers of new properties, which fits into the plan of central Bedfordshire [54]. The largest distribution type was dismissed because $87 \%$ of the new properties would be flats, and the growth in the CaMKOx arc was not expected to have a high density of dwellings [28]. There are many types of dwellings available such as detached, flat, mid terrace, semi-detached, and end terrace, and their distribution can also vary depending on the number of properties in new sites. The distribution of newly built dwellings in England was adopted for this study from NHBC (see Table 5).

Table 5. Distribution of newly built composition in England during the period 2014 - 2018 [55].

\begin{tabular}{lllll}
\hline Detached & Flat & Mid terrace & Semi detached & End terrace \\
\hline $19 \%$ & $42 \%$ & $9 \%$ & $20 \%$ & $10 \%$ \\
\hline
\end{tabular}

\subsubsection{Energy consumption by different dwelling types}

Depending on the type of dwellings and the occupancy rate, i.e. numbers of people living in it, energy consumption behaviours vary. Energy consumption data for this study was obtained from a survey of 250 dwellings, carried out by the Department of Energy and Climate Change (DECC) that was undertaken from May 2010 to July 2011 in England [56]. DECC monitored dwellings' electricity consumption at every 10 minutes interval. As a complement to the household electricity survey report, DECC also developed an interactive spreadsheet that allows user to work with the daily household consumption data, which can be found in [57]. Data about the type of dwelling as well as the daily electricity consumption profile obtained from DECC was used in this study. It is worth to noting that the survey was conducted almost a decade ago and hence the electricity consumption profile may well be different today, especially for lighting and appliances. Of all the dwelling types analysed by DECC, bungalows are the only type that does not match with either the actual distribution of new dwellings in England or the future English homes prediction of NHBC foundation [58]. Hence, this type of home was excluded in this study.

\section{Results}

Based on the methodology laid out in Section 2, this section provides results of the baseline and alternative scenarios of new housing developments of the Central Bedfordshire within the CaMKOx arc. An economic analysis of different scenarios and the impacts on the grid of new housing developments are also quantified and presented. 


\subsection{Baseline scenario}

From Eq. (2), the charging time of the representative EV was estimated to be $1 \mathrm{~h}$. Hence, the baseline demand was obtained by adding the 10-minute (yearly averaging) load profile data from DECC [56] to the EV charging requirement of $7 \mathrm{~kW}$ between the periods of 18:00 to 19:00 h. Fig. 5 shows the daily baseline load profile with an EV for all types of dwellings. These load profiles demonstrate the electricity use for a single day- representing the average profile over the year. It can be seen from the figure that charging the EV just when arriving home stresses the grid since it matches with the peak demand. However, in practice EVs charging can happen at any time of a day. Regardless of possible variations in plug-in timing, EVs in the baseline scenario would still be drawing electricity from the grid and the additional requirements would increase the dwellings' peak electricity demand significantly.

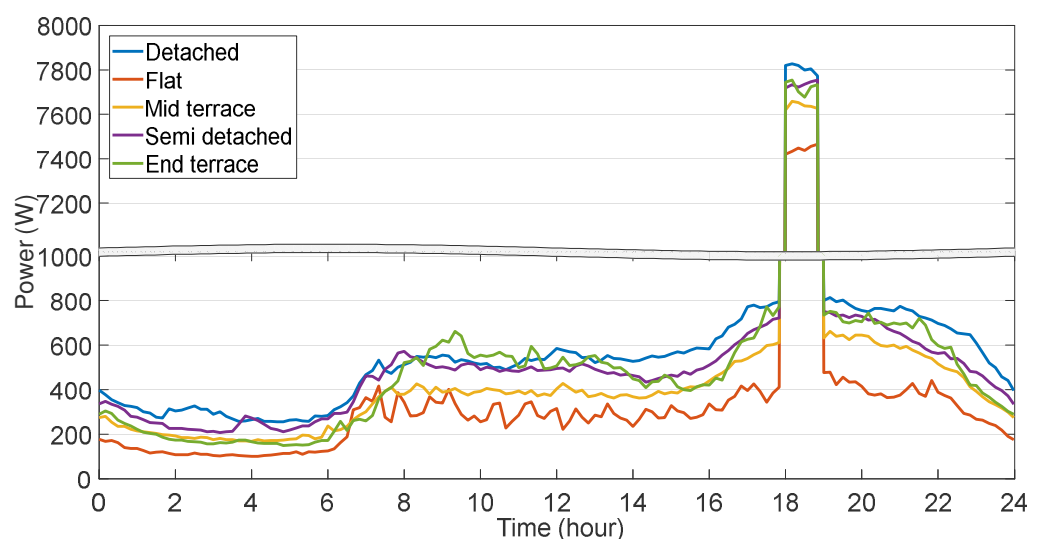

Fig. 5. Baseline electricity demand for a single day (average profile for a year) per dwelling types with an EV is plugged-in between 18:00 to 19:00 $\mathrm{h}$.

\subsection{Alternative scenarios}

In this scenario, solar PV and storage are adopted for all dwelling types. Unlike the baseline scenario, alternative scenarios allow the dwellers to charge their EVs directly from solar PV and battery storage. Table 6 shows the number of PV panels needed for each type of dwellings that are calculated from the annual and daily electricity demand (see Sections 2.2.1 and 2.2.2). As can be seen from the table the number of PV arrays with the annual consumption model in Eqs. (3-4) is around double for most of the dwelling than that of the daily consumption model. Also, the PV arrays with the annual consumption model need more roof spaces than available spaces for PV installation in typical English homes as discussed in Section 2.2. Hence, it appears that the number of PV panels with the annual consumption model is over-predicted due to a calculation method that considers the annual demand must be fully covered by PV output, without considering seasonal and daily solar radiation profiles.

The number of PV panels considering the daily electricity consumption (see Fig. 5 ) and solar radiation profiles (see Fig. 4 and Eqs. (5-7)) was evaluated and is shown in Table 6. It can be seen from the table that the number of PV panels calculated with this model is much less (maximum: 17 for a detached house and minimum: 9 panels for a flat) than the ones calculated by the annual consumption model. Also, the number of PV panels obtained for most of the dwellings are within the available space limits for PV installation in typical English homes discussed in Section 2.2. Due to the restriction of roof spaces and PV numbers, the annual generation in the daily consumption model is less than the annual 
demand for all dwelling types. It is to be noted that the annual yield from a single PV in the annual consumption model was around $300 \mathrm{kWh}$, which is around $22 \%$ lower than the generation in the daily consumption model. This is because of the slight differences in data used in this paper. Firstly, the $K_{k}$ $(\mathrm{kWh} / \mathrm{kWp})$ value used (see Table 2) for the calculation of annual yield in the annual consumption model was $20 \%$ less than the total potential values due to an assumption of reduced system performance [44]. Secondly, the $K_{k}$ values data in Table 2 was for Central Bedfordshire County, which covers a large geographical area. In contrast, the solar radiation data in the daily consumption model was the actual data recorded for Marston Moretaine, one of the studied areas in this research, without any system loss in it.

Fig. 6 shows the daily generation and consumption for each type of dwelling in daily consumption model. Each graph consists of the overall daily consumption including dwelling and EV demands, and daily generation by PV panels in typical UK weather conditions, for the most representative months, January and July.

Table 6. PV array output and size for different sizing models

\begin{tabular}{llllllll}
\hline \multirow{2}{*}{$\begin{array}{l}\text { Type of } \\
\text { dwelling }\end{array}$} & $\begin{array}{l}\text { Annual } \\
\text { electricity }\end{array}$ & \multicolumn{3}{c}{ Annual consumption model } & \multicolumn{3}{c}{ Daily consumption model } \\
\cline { 3 - 8 } & $\begin{array}{l}\text { Nomand } \\
(\mathrm{kWh})\end{array}$ & $\begin{array}{l}\mathrm{PV} \\
\text { panels* }\end{array}$ & $\begin{array}{l}\text { Roof area } \\
\text { needed } \\
\left(\mathrm{m}^{2}\right)\end{array}$ & $\begin{array}{l}\text { Annual } \\
\text { generation } \\
(\mathrm{kWh})\end{array}$ & $\begin{array}{l}\text { No. of } \\
\mathrm{PV} \\
\text { panels } \dagger\end{array}$ & $\begin{array}{l}\text { Roof area } \\
\text { needed } \\
\left(\mathrm{m}^{2}\right)\end{array}$ & $\begin{array}{l}\text { Annual } \\
\text { generation } \\
(\mathrm{kWh})\end{array}$ \\
\hline Detached & 7173 & 24 & 40.08 & 7173 & 17 & 28.4 & 6210 \\
Flat & 4969 & 17 & 28.39 & 4969 & 9 & 15 & 3287 \\
Mid terrace & 5930 & 20 & 33.40 & 5930 & 11 & 18.4 & 4019 \\
Semi detached & 6654 & 22 & 36.74 & 6654 & 12 & 20 & 4384 \\
End terrace & 6483 & 22 & 36.74 & 6483 & 11 & 18.4 & 4019 \\
\hline
\end{tabular}

* Number of PV panels in annual consumption model is the maximum PV modules needed to cover full annual electricity demand by dwellings.

$\dagger$ Number of PV panels in daily consumption model was restricted by the available spaces for PV installation on a rooftop of dwellings.
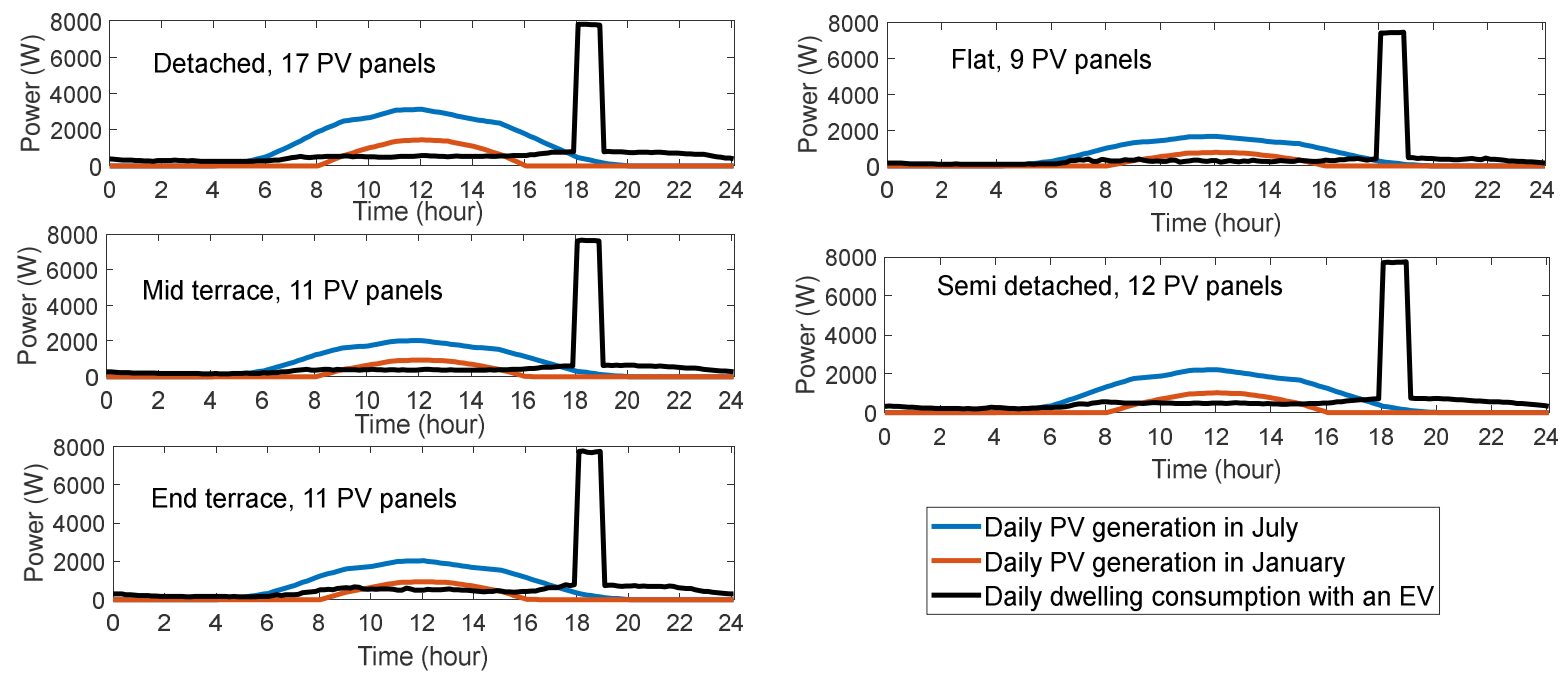
Fig. 6. Daily electricity generation and consumption profiles for dwellings in typical UK weather conditions in July and January.

Since all types of dwellings had peak demand at around 18:00 $\mathrm{h}$ when the PV generation is very low (based on monthly average solar irradiation profile), the model was designed such that batteries stored excess electricity from PV from the beginning of generation and continued until they were fully charged. Once PV generation had stopped or could not meet the full demand, any excess demand would, ideally, be met by batteries, depending on the size and availability of stored power. In the same cases, it was not possible to supply all electricity from PV and storage due to the variation of generation across the days, months and seasons. Hence any excess demand not met by PV and storage was supplied by the grid. On the other hand, it is also true that in some months of a year, for example during the summer months, there was excess generation from PV with storage that was then supplied back to the grid. For all types of dwellings displayed in Fig. 6, the storage size can be determined in two ways: the maximum and the optimal size (see Fig. 7, which shows the storage size for a detached house), as discussed in Section 2.2.3. The maximum size stored all the excess energy generated by PV that was not used during the day. However, the maximum size obtained could not discharge all the stored electricity during the night due to insufficient demand. Hence, at the end of the day, some of the stored energy remained, and batteries had to compromise their abilities to capture all excess generation on the following day. The optimal system did not store electricity from one day to another. Instead, the stored electricity was fully discharged at the end of the day. For example, the maximum battery size for a detached house was found to be $19.15 \mathrm{kWh}$. At this capacity the battery was able to discharge only $10.90 \mathrm{kWh}$ by the end of a typical July day, which gave a capacity factor of $56.92 \%$ only. Rest of the charge, $8.25 \mathrm{kWh}$, was unused on the day the charge was stored (see Fig. 7(a)). In contrast, the optimal battery was able to fully discharge (See Fig. $7(a, b)$ ) and restore a $100 \%$ capacity factor to make it ready to store the excess generation from PV on the next day. Table 7 presents the capacity of the batteries (maximum and optimal) needed for each type of dwellings and their corresponding capacity factors. Based on the optimal size requirements of storage in Table 7, Powervault 3 (capacity: $12.3 \mathrm{kWh}$ [59]) was selected for all dwellings except flats. Since the flat needs an optimum size of $9.03 \mathrm{kWh}$, LG Chem RESU 10 (capacity $9.8 \mathrm{kWh}[60])$ was selected.
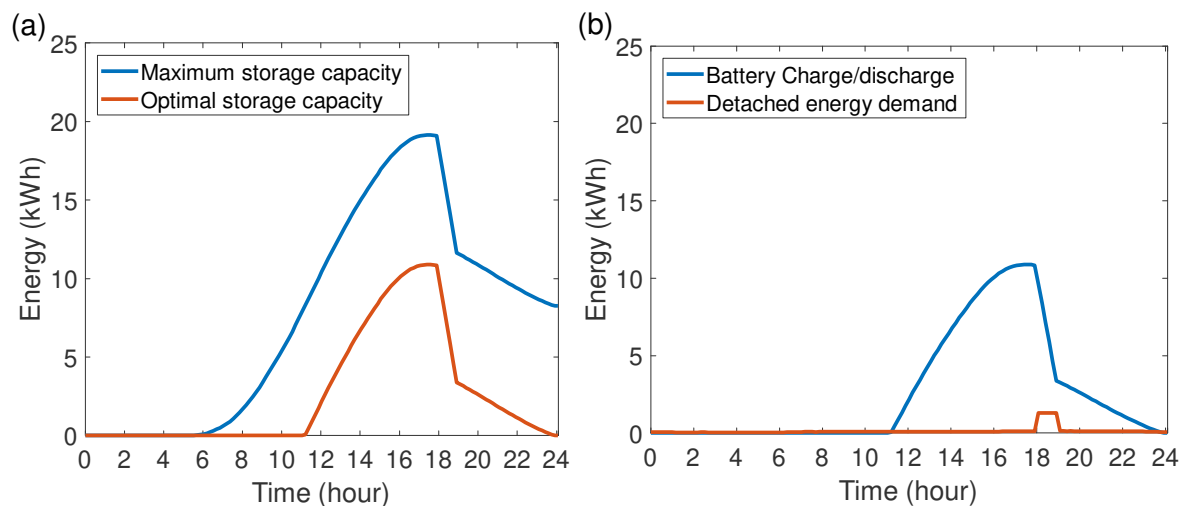

Fig. 7. Sizing storage requirement and energy management for a detached house: (a) charging and discharging with maximum and optimal storage size, (b) charging and discharging with optimal storage against dwelling's energy demand. 
Table 7. Storage system capacity per type of dwelling.

\begin{tabular}{lllll}
\hline \multirow{2}{*}{ Type of dwelling } & \multicolumn{2}{c}{ Maximum storage sizing } & \multicolumn{2}{c}{ Optimal Storage sizing } \\
\cline { 2 - 5 } & Capacity $(\mathrm{kWh})$ & Capacity factor & Capacity $(\mathrm{kWh})$ & Capacity factor \\
\hline Detached & 19.15 & $56.92 \%$ & 10.90 & $100 \%$ \\
Flat & 10 & $90.30 \%$ & 9.03 & $100 \%$ \\
Mid terrace & 11.90 & $84.62 \%$ & 10.07 & $100 \%$ \\
Semi detached & 12.24 & $86.20 \%$ & 10.55 & $100 \%$ \\
End terrace & 10.90 & $97.24 \%$ & 10.60 & $100 \%$ \\
\hline
\end{tabular}

\subsection{Economic analysis}

In this section, the monthly electricity costs associated with the baseline scenario are compared to the costs of scenarios with PV and storage system taking advantage of Economy 7 and FIT tariffs. In addition, an economic analysis of post-FIT SEG scheme is also included. The cost of PV panels and storage used in this research are shown in Table 8. Energy storage cost is the largest contributor to total cost and the installation cost of storage was included in the price of the device. The economic analysis in alternative scenarios were conducted with and without having a subsidy scheme for battery storage. A further analysis assuming a reduction of storage price was also conducted to evaluate economic viability of PV plus storage for dwellings with an EV. Two different batteries but with same performance indicators were used (see Table 8). Powervault 3 and RESU 10 batteries can offer over 6,000 cycles and were estimated to last 13 years [59]. Since the PV panels have a warranty of 25 years and the battery is expected to last 13 years, the battery must be replaced once during the lifetime of PV panels. Therefore at the end of the $13^{\text {th }}$ year, a replacement battery and its associated cost were added in the total investment cost. Since battery prices are decreasing up to $18 \%$ pa [47], the replacement cost for batteries at year $13^{\text {th }}$ was corrected to take advantage of the predicted discounted cost.

Table 8. Prices and warranty of different components.

\begin{tabular}{llll}
\hline Component & Price $(£) /$ piece * & Warranty (years) & Installation cost $(£)$ \\
\hline N310K Photovoltaic Module & 450 & 25 & 500 \\
HIT® BLACK of Panasonic [43] & & & \\
Powervault 3, 12.3 kWh [61] & $8090[62]$ & 10 & Included in price \\
LG Chem RESU 10, 9.8 kWh [60] & $6100[62]$ & 10 & Included in price \\
\hline
\end{tabular}

* All prices include 5\% UK sales tax (VAT)

Table 9 displays average grid consumption per month, PV generation and cost of electricity for baseline and alternative scenarios. In alternative scenarios, the monthly bill was calculated by subtracting the FIT money from the cost of day and night electricity from the grid. Comparing the cost of electricity with PV and storage by taking advantage of FIT and Economy 7 with the cost without having them, it can be seen that using low carbon technologies not only reduces monthly bills significantly in January but also generates income by net exporting electricity to the grid in July. In January, the maximum reduction of $46 \%$ was for a detached house, which was due to a lower amount of grid electricity use, whereas the minimum reduction was for flats at $19 \%$ with Economy 7 and FIT. On the other hand, for the similar tariff structure in July, all the dwellings generate income for the dwellers by net exporting electricity to 
the grid. In cash terms, the maximum income was for detached house at $£ 29.8$ and the minimum was for flats at $£ 6.4$.

With Economy 7 and Economy 7 plus load shifting options in July, every dweller earned more money from FIT than it expended on purchasing grid electricity (see Table 9). It can be seen that the electricity costs in alternative scenarios in July do no vary due to the fact that in both cases dwellings were producing more electricity than they required and there was no need for purchasing grid electricity at night for the use in the day. Whereas in January the opposite is true, with more electricity purchased than money received from the FIT. However, if we compare the January bills using the Economy 7 and load shifting for different dwellings with the ones obtained using Economy 7 only, we can see that load shifting with storage reduces January's electricity bill significantly. Nevertheless, until the grid has more renewable energy, the use of grid energy may not help to reduce emissions, even though it reduces dwellers' electricity bills.

Table 9. Economic cost comparisons between baseline and alternative scenarios.

\begin{tabular}{|c|c|c|c|c|c|c|c|c|}
\hline \multirow{3}{*}{ House type } & \multicolumn{2}{|c|}{ Baseline scenario } & \multicolumn{6}{|c|}{ Alternative scenarios with PV, storage and FIT } \\
\hline & \multirow[t]{2}{*}{$\begin{array}{l}\text { Grid } \\
\text { consumption/ } \\
\text { month }^{\dagger}\end{array}$} & \multirow[t]{2}{*}{$\begin{array}{l}\text { Electricity } \\
\text { cost/ } \\
\text { month }\end{array}$} & \multicolumn{2}{|c|}{$\mathrm{PV}_{\text {generation }}^{+}$} & \multicolumn{2}{|c|}{$\begin{array}{l}\text { Electricity cost* } \\
\text { with Economy } 7\end{array}$} & \multicolumn{2}{|c|}{$\begin{array}{l}\text { Electricity cost } \\
\text { with Economy } 7 \\
\text { and load shifting }\end{array}$} \\
\hline & & & January & July & January & July & January & July** \\
\hline & $\mathrm{kWh}$ & (£) & $(\mathrm{kWh})$ & $(\mathrm{kWh})$ & (£) & (£) & (£) & (£) \\
\hline Detached & 609.2 & 97.5 & 235 & 820 & 52.61 & -29.8 & 34.4 & -29.8 \\
\hline Flat & 422 & 70.4 & 124 & 434 & 57.2 & -6.4 & 40.3 & -6.4 \\
\hline Mid terrace & 503.6 & 82.2 & 152 & 531 & 64.3 & -10 & 42.5 & -10 \\
\hline Semi detached & 565.2 & 91.1 & 166 & 579 & 69.2 & -10.6 & 47 & -10.6 \\
\hline End terrace & 550.6 & 89 & 152 & 531 & 68.1 & -8.7 & 44.6 & -8.7 \\
\hline
\end{tabular}

${ }^{\dagger}$ Monthly average consumption

${ }^{+}$Electricity generation with the number of PV panels obtained by daily consumption model in Table 6

$*$ Cost of electricity $=$ Cost of electricity purchased from the grid, the net figure is reduced by FIT received

** The cost of electricity in July with Economy 7 and load shifting is negative, which means dwellers were receiving more money from FIT than what they were spending to purchasing electricity from the grid.

The depreciation of PV and battery storage installation was calculated from the cost of all the devices shown in Table 8 and the cost of the electricity with and without PV and storage shown in Table 9. Table 10 summarises the savings of using PV and storage per year with Economy 7 and FIT and Economy 7 with load shifting and FIT. It is evident that in both cases PV and storage could avoid a significant monthly cost, even after deducting the cost of investment and taking storage degradation into account. However, with these amount of savings the cost of investment on PV and storage without having a subsidy on storage could not be recuperated in 25 years (NPV for all dwellings after 25 years were negative). A mid terrace house was expected to make a maximum loss of $£ 5207$ with Economy 7 while $£ 4231$ with Economy 7 and load shifting. On the contrary, if we assumed that $50 \%$ of the storage cost would be subsidised by the Government, a similar scheme available in Italy [63], the economic indicators could turn into positive. In such a case, all dwellings could make profit using Economy 7 and FIT scheme, except flats and mid terrace houses which is due to more grid electricity use than they could 
generate (see Table 10 and Fig. 8(a). Figures in Table 10 show that all houses in this study using FIT, Economy 7 and load shifting with 50\% subsidy on storage made a profit, which is also supported by the NPV in Fig. 8 (b). It can be seen from this figure that all types of houses recuperated the investment and offered net profits over the lifetime of the installations, generally hitting a payback period of 16 years for a detached house and about 18-19 years for all other houses in Economy 7, FIT and load shifting option (see Fig. 8(b)).

Table 10. Annual bills avoided and profit of using PV and storage systems.

\begin{tabular}{|c|c|c|c|c|c|c|}
\hline \multirow[t]{3}{*}{ Dwelling type } & \multicolumn{3}{|c|}{ Economy 7 and FIT } & \multicolumn{3}{|c|}{ Economy 7 with load shifting and FIT } \\
\hline & \multirow{2}{*}{$\begin{array}{l}\text { Bills } \\
\text { avoided/ } \\
\text { Year*, } \\
\text { (£) }\end{array}$} & \multicolumn{2}{|c|}{$\begin{array}{l}\text { NPV of profit/loss of PV and } \\
\text { storage after } 25 \text { years, }(\mathfrak{E})\end{array}$} & \multirow{2}{*}{$\begin{array}{l}\text { Bills } \\
\text { avoided/ } \\
\text { Year*, } \\
\text { (£) }\end{array}$} & \multicolumn{2}{|c|}{$\begin{array}{l}\text { NPV of profit/loss of PV and } \\
\text { storage after } 25 \text { years, }(\mathfrak{f})\end{array}$} \\
\hline & & $\begin{array}{l}\text { No subsidy } \\
\text { on storage }\end{array}$ & $\begin{array}{l}50 \% \text { subsidy } \\
\text { on storage }\end{array}$ & & $\begin{array}{l}\text { No subsidy } \\
\text { on storage }\end{array}$ & $\begin{array}{l}50 \% \text { subsidy on } \\
\text { storage }\end{array}$ \\
\hline Detached & 1033 & -2232 & 3242 & 1142 & -1450 & 4024 \\
\hline Flat & 540 & -3728 & -231 & 641 & -2944 & 1183 \\
\hline Mid terrace & 661 & -5207 & -590 & 791 & -4231 & 1243 \\
\hline Semi-detached & 741 & -4430 & 218 & 874 & -3385 & 2089 \\
\hline End terrace & 712 & -4434 & 202 & 852 & -3279 & 2195 \\
\hline
\end{tabular}

*The bill savings presented here is for year 1. The successive years' bill savings would be less than that of year 1 due to battery degradations, which was included in the NPV calculation.
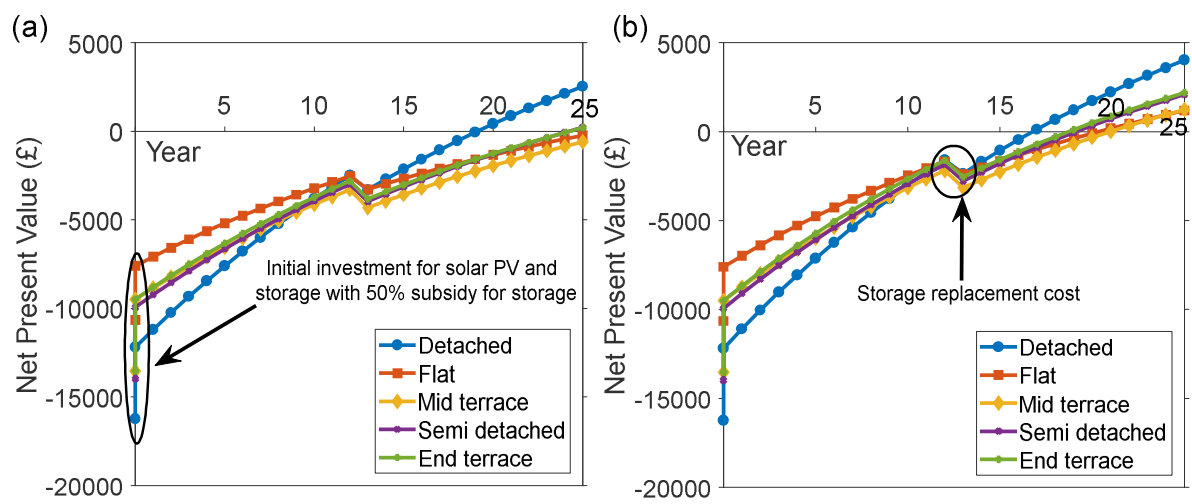

Fig. 8. Net present value distribution of solar PV and storage over a period of 25 years (a) with Economy 7 and FIT and (b) Economy 7 with load shifting and FIT

The economic performance of PV and storage with having a 50\% subsidy on storage in the post-FIT scheme is shown in Fig. 9. If the FIT is phased out and to be updated by SEG and paid a PV generator at the rate equal to FIT's export tariff, none of the houses make profits except a detached house in Economy 7 with load shifting (see Fig. 9(a)), due to their lower generation and export to the grid. If we reduce SEG tariff by 50\%, all dwellings would be in net loss for combined solar PV and storage investment (see Fig. 9(b)). Fig. 9(c) shows that if SEG increases by 50\%, still all dwelling would be in loss except a detached house with Economy 7 and load shifting option. This similar trend can also be observed in SEG which increases by 100\% from the FIT's export tariff, though the loss of investment for houses were reduced and the profit for a detached house were increase slightly (see Fig. 9(d)). 
Since the economic performance of PV and storage with 50\% subsidy was not satisfactory, a further analysis was then conducted by assuming potential reduction of storage cost along with $50 \%$ subsidy. The outcomes of this scenarios is shown in Fig. 10. It is evident that with the reduction of storage cost from $15 \%$ to $60 \%$ and having a $50 \%$ subsidy on storage improve the economic performance significantly. With a $45 \%$ reduction in battery cost and 50\% subsidy, all dwellings in Economy 7 and load shifting make profits (Fig. 10(c), while a $60 \%$ reduction in battery cost guarantee a profit for all dwellers in both the Economy 7 and Economy 7 plus load shifting (Fig. 10(d)).
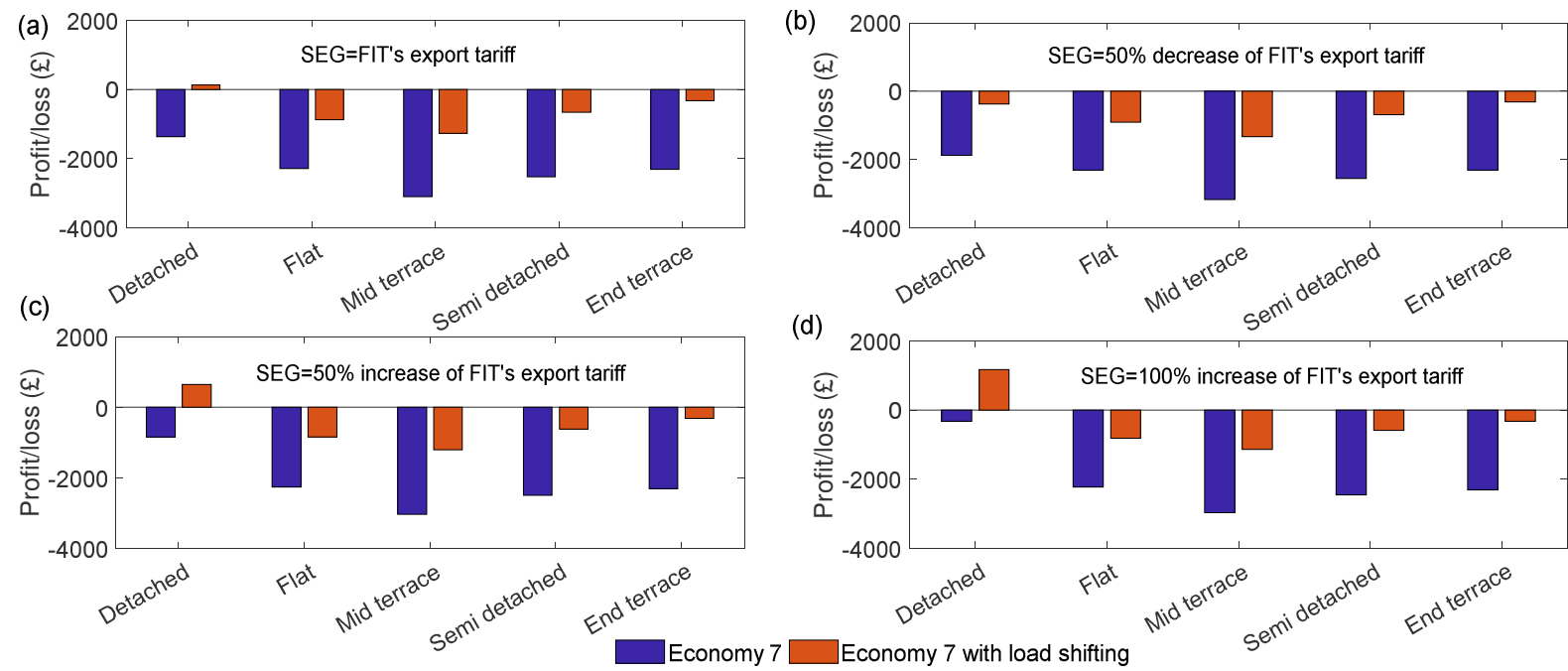

Fig. 9. Profit/loss of PV and storage in Economy 7 and Economy 7 with load shifting with $50 \%$ subsidy for storage and potential tariff rates of Smart Export Guarantee (SEG) schemes: a) assuming SEG export tariff will be the same as that of FIT, (b) SEG $=50 \%$ decrease of FIT export tariff, (c) SEG $=50 \%$ increase of FIT export tariff and (d) SEG $=100 \%$ increase of FIT export tariff.
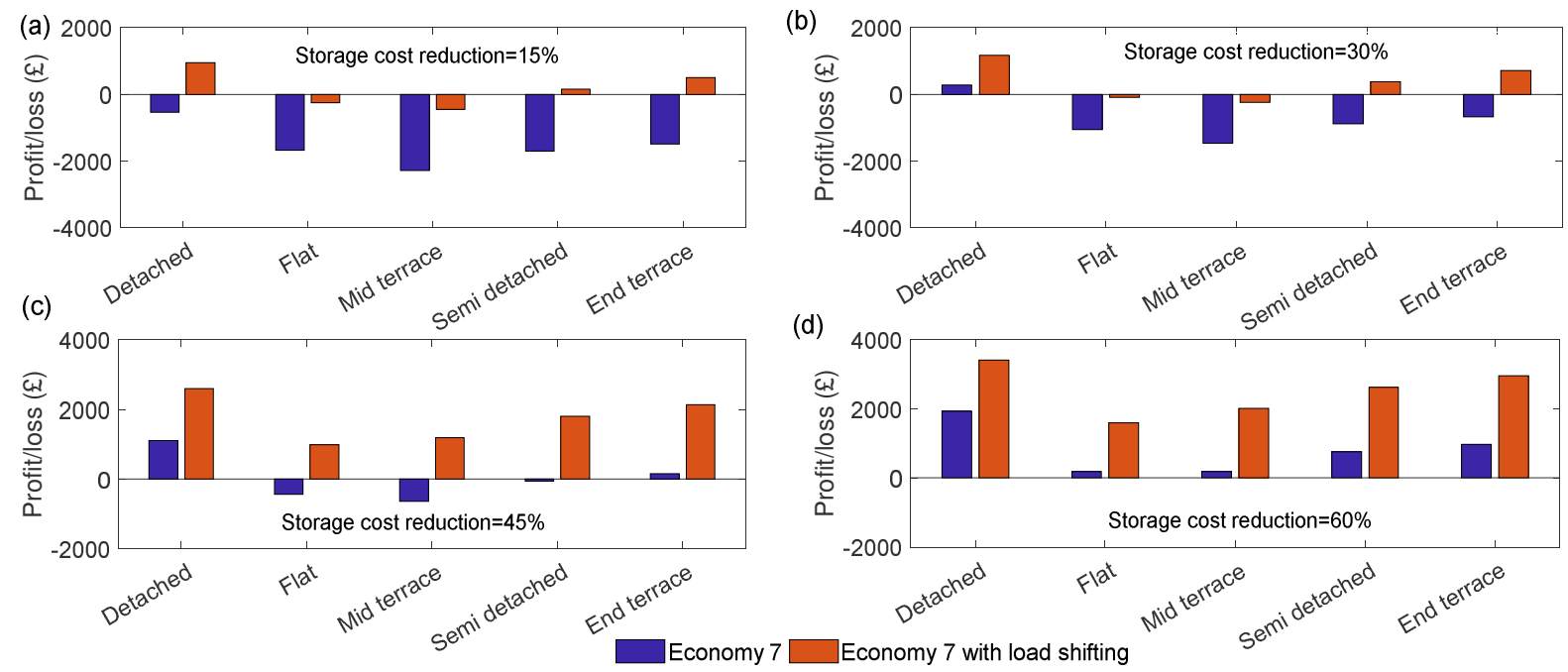

Fig. 10. Profit/loss of PV and storage in Economy 7 and Economy 7 with load shifting with fixed SEG $=$ FIT's export tariff and assuming 50\% subsidy on storage along with (a) 15\% reduction of storage cost 
(b) $30 \%$ reduction of storage cost, (c) $45 \%$ reduction of storage cost, and (d) $60 \%$ reduction of storage cost

\subsection{Grid impact of new growth within CaMKOx arc}

The new housing developments in the region east of Biggleswade, and the four new villages in Marston Moretaine, north of Luton and east of Arlesey will have a significant impact on the grid. Assuming that the distribution of dwelling type is the same as the one shown in Table 5 and that every dwelling has an $\mathrm{EV}$, the overall grid impact with and without using PV and storage for selected areas in the CaMKOx arc is shown in Fig. 11. It can be seen from this figure that the grid electricity demand for new housing sites has increased significantly without PV and storage. The highest electricity demand (daily average) from grid is for Marston Moretaine, which is $81.60 \mathrm{MWh} /$ day, followed by north of Luton (65.34 $\mathrm{MWh} /$ day), east of Arlesey (32.65 MWh/day) and east of Biggleswade (24.50 MWh/day). On the other hand, the grid impact of new housing developments on these areas with the inclusion of PV and storage varies depending on a month. Since the electricity generation from solar in the month of January and July differ significantly, we compared the grid impact of these months separately. Comparing these results it can be seen that in the months with more solar generation such as July, the net electricity consumption from the grid is negative for all the housing areas considered. That means, these housing areas would be producing more electricity than they could consume and hence they would become a net exporter of electricity to the grid in July. In total all four housing areas (comprises 12500 different types of dwellings) was expected to supply an estimated 19.47 MWh/day to the grid if low carbon technologies like PV panels and energy storage systems were installed. In the cloudy months like January, the impact on the grid could be reduced up to $31 \%$ (from $204.11 \mathrm{MWh} /$ day to $140.07 \mathrm{MWh} /$ day).

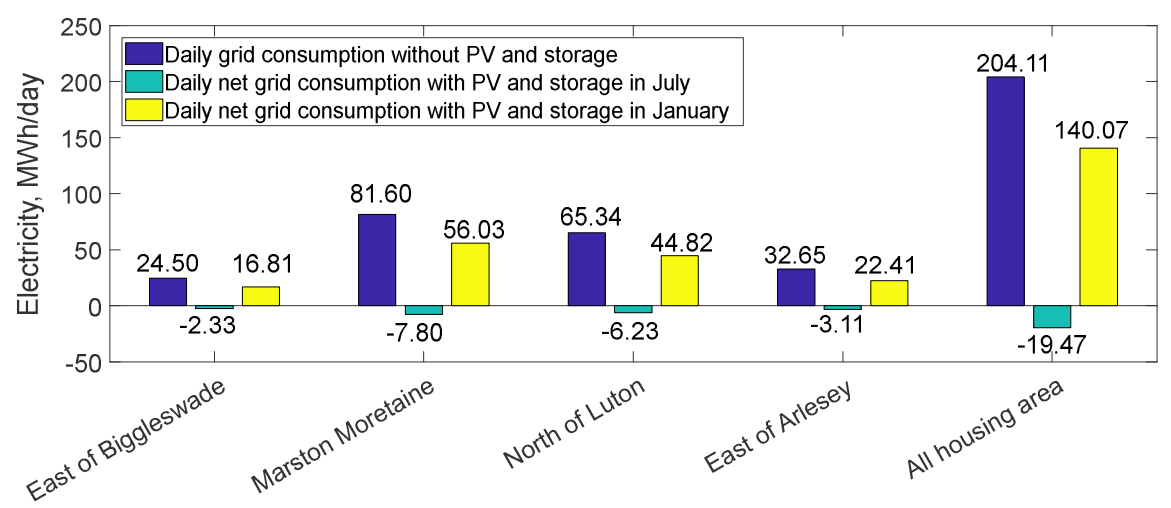

Fig. 11. Assuming that every dwelling has an EV, the grid impact of new housing developments with and without PV and storage for selected areas in the CaMKOx arc.

\section{Discussion}

The baseline scenario, which consists of electricity demand for dwellings including EVs load that are met by the grid, places significant extra demand on the grid. From a cost perspective, cost is the same to use electricity any time of a day, or charge EVs at $7 \mathrm{~kW}$ for one hour or longer at a lower charging power, since the price of electricity with standard tariff is always the same. From a grid perspective, it is necessary to distribute dwellings and, especially, EVs demand as much as possible away from the peak to avoid overstressed peak demand. Fortunately, people have different routines and arrive homes at different times, and hence EVs charging time is dispersed in practice. Kuihua et al. [64], after 
assessing different scenarios on charging modes, concluded that by 2030 the main EV charging load will take place in the morning or the evening, just before or after the dwelling peak demand time. National Grid [10] forecasts that only one in five dwellings would charge the EV at peak hours. Besides, there is also a diversity of charging places: not all EV owners will charge EVs at home, some will charge at workplaces while others at public charging points [39]. However, the models used in these works were based on assumptions that EVs would charge with the grid electricity. Therefore we argue that if they were to consider a scenario that every dwelling has its electricity generation from solar PV and have storage for storing excess electricity, it is likely that most of the people would charge their EVs at home.

On the other hand, demand-side response via differentiated tariffs such as Economy 7 for EV charging could be an option to shift EVs load away from dwellings' peak. The uptake of EVs will likely increase the use of cheaper night tariffs in residential areas and, therefore, increasing electricity consumption during the night. Pimm et al. [65] showed that staggering prices into bands at off-peak times will help to offset the rebound effect where new peaks might emerge on the grid.

The alternative scenarios studied in this paper, which is similar to the requirement in the State of California where newly built homes after January 1, 2020 will include PV systems [66], show that installing PV panels in new houses along the arc reduced the grid electricity demand significantly. Our results show that PV systems need energy storage devices to balance the intermittency of solar energy and thus match energy generation with consumption. Under the current FIT and SEG schemes, dwellers are not able to earn monies if they were to supply electricity from storage. We found that supplying electricity from storage for in-house consumptions during the night was financially beneficial as it could avoid the use of grid electricity. Our study shows a practical benefit of installing stationary batteries in new housing developments such as the CaMKOx arc and others around the world.

The strategy proposed in this research (and checked with the economic analysis) of charging the battery during off-peak hours and discharging it during peak period is viable only when there exists an Economy 7 or similar tariff structures. This off-peak/peak charging/discharging scenario does not maximise revenue or energy efficiency without taking into account different night/day tariffs, rather as supported by Nottrott et al. [67] it can help to manage peak demand during the day.

It was observed that the cost of battery storage has a significant influence on the NPV of PV and storage for dwellings with an EV. With the current FIT and no subsidy for storage in the UK, investment on PV and storage is not a viable option. Nonetheless, a Government subsidy of 50\% on storage could alter the economic outcomes. Since the FIT came to an end for new applicants in April 2019, the economic analysis of post-FIT was conducted with a new SEG scheme. Our study shows that without $50 \%$ subsidy and up to $60 \%$ reduction of storage cost, investment on PV and storage will not be making any profit for most of the dwellings. To investigate the economics and the effects of depreciation of the PV panels and batteries, actual electricity prices were used and considered that they will remain the same in the future. Over the last few years, the retail price of electricity at the domestic level has increased slightly in the UK due to energy systems decarbonisation policies such as carbon price and renewable subsidies [68]. It is also expected that the electricity price will increase steadily in future. Any adjustment in the 
economic analysis to account for different future electricity prices may alter the results presented in this work.

Apart from the traditional schemes for selling and buying electricity to and from the grid, a Peer-to-Peer (P2P) energy trading scheme may be a potential option for prosumers in new housing developments. Since it was assumed that every dwelling has PV and storage along the arc, the chance of trading energy with other prosumers may be reduced. Therefore the P2P scheme was not considered in our research.

The data and subsequent results from models presented in this paper were obtained by analysing published data from an English dwelling study conducted by DECC [56]. Energy profiles were categorised by type of dwelling. Thus, an average load profile was assumed for each type of dwelling, without taking into account occupancy or differences in energy behaviours [69] and values [70]. Electricity consumption and use profile has a direct relationship with people's habits and since EVs are still relatively sparse there is an opportunity to influence the creation of new habits toward off-peak charging. Whilst energy cost is greater for more occupants, there are efficiencies for larger houses if they are fully occupied. Further research on electricity profiles for each dwelling type considering its occupancy and household energy behaviour is needed.

\section{Conclusions}

This study optimised renewable energy integration for new housing developments and compared the technical and economic benefits of dwellings having solar PV and storage. The uptake of EVs in new housing developments increases each dwelling's electricity demand and therefore, the demand on the grid. This study shows that low carbon technologies, such as PV panels coupled with batteries, provide a mechanism to counteract the effect of EVs on the grid as well as help to decarbonise the energy system.

Storage systems can support the grid when it is under peak load and help to maximise the value of installed solar energy systems. They reduce the demand from the grid by storing free solar electricity and help to reduce energy bills by storing cheap off-peak electricity from the grid. Moreover, dwellings can take advantage of the feed-in tariff incentives, which consists of payments for generating and exporting solar energy to the grid. It was estimated that every dwelling would be avoiding significant amount of bills for grid electricity use- the highest was for detached houses (£1142/year) and the lowest for flats (£641/year). With the Economy 7, feed-in tariff and load shifting options, all dwellings studied in this research could get a payback period of around 16 to 19 years for all investment on PV and storage, provided that a half of the battery cost was subsidised. In a post-feed-in tariff situation in the UK, the smart export guarantee scheme cannot make the PV and storage system profitable, unless the battery cost is reduced significantly and the subsidy scheme is in place. However, the amount of energy savings or losses varies depending on the types of dwellings and the uncertain generosity of the new incentive and subsidy schemes. Despite the uncertainty, it is possible that some households are not profitmotivated and will still invest based on environmental or social motives of decarbonisation or community resilience [71]. In terms of grid impact, the adoption of PV and storage in new housing sites not only reduces the grid electricity demand but also could supply a large amount of green electricity to the grid. For instance, in July, new housing sites could become a net exporter of electricity by potentially supplying 19.47 MWh/day from the four new housing sites studied in this paper. 


\section{Acknowledgements}

This work was supported by the Engineering and Physical Sciences Research Council (EPSRC, EP/P004636/1, UK). The EPSRC grant is gratefully acknowledged.

\section{References}

[1] S. Walker, T. Labeodan, G. Boxem, W. Maassen, W. Zeiler, An assessment methodology of sustainable energy transition scenarios for realizing energy neutral neighborhoods, Appl. Energy. 228 (2018) 2346-2360. doi:10.1016/j.apenergy.2018.06.149.

[2] L. Belussi, B. Barozzi, A. Bellazzi, L. Danza, A. Devitofrancesco, C. Fanciulli, M. Ghellere, G. Guazzi, I. Meroni, F. Salamone, F. Scamoni, C. Scrosati, A review of performance of zero energy buildings and energy efficiency solutions, J. Build. Eng. $25 \quad$ (2019) 100772. doi:10.1016/j.jobe.2019.100772.

[3] BEIS, Energy Consumption in the UK, London, 2018. doi:10.1073/pnas.1423686112.

[4] The UK government, Climate Change Act 2008, United Kingdom, 2018.

[5] BEIS, UK becomes first major economy to pass net zero emissions law, (2019). https://www.gov.uk/government/news/uk-becomes-first-major-economy-to-pass-net-zeroemissions-law (accessed June 27, 2019).

[6] M.F. Astudillo, K. Vaillancourt, P. Pineau, B. Amor, Can the household sector reduce global warming mitigation costs? sensitivity to key parameters in a TIMES techno-economic energy model, Appl. Energy. 205 (2017) 486-498. doi:10.1016/j.apenergy.2017.07.130.

[7] S. Vilcekova, I. Selecka, E.K. Burdova, Sustainability Assessment of Family House, Energy Procedia. 96 (2016) 551-559. doi:10.1016/j.egypro.2016.09.098.

[8] BEIS, 2017 UK Greenhouse gas emissions, London, 2019.

[9] DfT, The Road to Zero: Next steps towards cleaner road transport and delivering our Industrial Strategy, London, 2018.

[10] National Grid, Future Energy Scenarios 2018, London, 2018.

[11] P. Paevere, A. Higgins, Z. Ren, Spatio-temporal modelling of electric vehicle charging demand and impacts on peak household electrical load, (2014) 61-76. doi:10.1007/s11625-013-0235-3.

[12] J.I. Chowdhury, N. Balta-Ozkan, P. Goglio, Y. Hu, L. Varga, L. McCabe, Techno-environmental analysis of battery storage for grid level energy services, Renew. Sustain. Energy Rev. 131 (2020) 110018. doi:10.1016/j.rser.2020.110018.

[13] C. Hachem, Impact of neighborhood design on energy performance and GHG emissions, Appl. Energy. 177 (2016) 422-434. doi:10.1016/j.apenergy.2016.05.117.

[14] N. Anisimova, The capability to reduce primary energy demand in EU housing, Energy Build. 43 (2011) 2747-2751. doi:10.1016/j.enbuild.2011.06.029.

[15] Y. Ko, The effect of urban form and residential cooling energy use in Sacramento, California, 41 (2014) 573-593. doi:10.1068/b12038p.

[16] D.K. Serghides, M. Michaelidou, M. Christofi, S. Dimitriou, M. Katafygiotou, Energy Refurbishment Towards Nearly Zero Energy Multi-Family Houses , for Cyprus, 38 (2017) 1119. doi:10.1016/j.proenv.2017.03.068.

[17] S. Silvester, S. Kumar, A. Van Timmeren, P. Bauer, J. Quist, S. Van Dijk, Exploring design scenarios for large-scale implementation of electric vehicles; the Amsterdam Airport Schiphol case, J. Clean. Prod. 48 (2013) 211-219. doi:10.1016/j.jclepro.2012.07.053.

[18] H.C. Curtius, The adoption of building-integrated photovoltaics : barriers and facilitators, 126 
(2018) 783-790. doi:10.1016/j.renene.2018.04.001.

[19] S.P. Ayeng'o, T. Schirmer, K.P. Kairies, H. Axelsen, D. Uwe Sauer, Comparison of off-grid power supply systems using lead-acid and lithium-ion batteries, Sol. Energy. 162 (2018) 140152. doi:10.1016/j.solener.2017.12.049.

[20] M. Ala-Juusela, T. Crosbie, M. Hukkalainen, Defining and operationalising the concept of an energy positive neighbourhood, Energy Convers. Manag. 125 (2016) 133-140. doi:10.1016/j.enconman.2016.05.052.

[21] H. Strasser, J. Kimman, A. Koch, O. Mair am Tinkhof, D. Müller, J. Schiefelbein, C. Slotterback, IEA EBC annex 63-implementation of energy strategies in communities, Energy Build. 158 (2018) 123-134. doi:10.1016/j.enbuild.2017.08.051.

[22] B.G. Nichols, K.M. Kockelman, Life-cycle energy implications of different residential settings : Recognizing buildings, travel, and public infrastructure, Energy Policy. 68 (2014) 232-242. doi:10.1016/j.enpol.2013.12.062.

[23] M.R. Shammin, R.A. Herendeen, M.J. Hanson, E.J.H. Wilson, A multivariate analysis of the energy intensity of sprawl versus compact living in the U.S. for 2003, Ecol. Econ. 69 (2010) 2363-2373. doi:10.1016/j.ecolecon.2010.07.003.

[24] C. Ratti, N. Baker, K. Steemers, Energy consumption and urban texture, Energy Build. 37 (2005) 762-776. doi:10.1016/j.enbuild.2004.10.010.

[25] M. Silva, Urban Form and Energy Demand : A Review of Energy-relevant Urban Attributes, J. Plan. Lit. 32 (2017) 346-365. doi:10.1177/0885412217706900.

[26] Ofgem, Domestic Renewable Heat Incentive (RHI), (2018). https://www.ofgem.gov.uk/environmental-programmes/domestic-rhi.

[27] BEIS, Feed-in tariffs: get money for generating your own electricity, (2019). https://www.gov.uk/feed-in-tariffs (accessed May 24, 2019).

[28] NIC, Cambridge , Milton Keynes and Oxford Future Planning Options Project, London, 2018.

[29] National Grid, Heating our homes, (2014). https://www.nationalgrid.com/group/news/heatingour-homes (accessed July 18, 2019).

[30] WWW.GOV.UK, Spring Statement 2019: Philip Hammond's speech, (2019). https://www.gov.uk/government/speeches/spring-statement-2019-philip-hammonds-speech (accessed May 21, 2019).

[31] Y. Li, W. Gao, X. Zhang, Y. Ruan, Y. Ushifusa, F. Hiroatsu, Techno-economic performance analysis of zero energy house applications with home energy management system in Japan, Energy Build. 214 (2020). doi:10.1016/j.enbuild.2020.109862.

[32] M. Chaudry, M. Abeysekera, S.H.R. Hosseini, N. Jenkins, J. Wu, Uncertainties in decarbonising heat in the UK, Energy Policy. 87 (2015) 623-640. doi:10.1016/j.enpol.2015.07.019.

[33] T. Nguyen, L. Gustavsson, A. Dodoo, U.Y.A. Tettey, Implications of supplying district heat to a new urban residential area in Sweden, Energy. $194 \quad$ (2020) 116876. doi:10.1016/j.energy.2019.116876.

[34] J.I. Chowdhury, Y. Hu, I. Haltas, N. Balta-Ozkan, G.J. Matthew, L. Varga, Reducing industrial energy demand in the UK: A review of energy efficiency technologies and energy saving potential in selected sectors, Renew. Sustain. Energy Rev. 94 (2018) 1153-1178. doi:10.1016/j.rser.2018.06.040.

[35] Ministry of Housing Communities and Local Government, The Future Homes Standard, London, 2019. 
[36] DfT, Vehicle licensing statistics: 2018, London, 2018.

[37] DfT, National Travel Survey: England 2016, London, 2017.

[38] HM Government, Electric Vehicle Charging in Residential and Non-Residential Buildings, London, 2019.

[39] S. Jennings, R. Parkin, A. Del Maestro, Charging ahead! The need to upscale UK electric vehicle charging infrastructure, 2018.

[40] Energy Saving Trust, Solar Energy Calculator Sizing Guide, (2015). https://www.pvfitcalculator.energysavingtrust.org.uk/Documents/150224_SolarEnergy_Calcul ator_Sizing_Guide_v1.pdf.

[41] University of Calgary, Multi-storey Building Design, (2018). https://www.ucalgary.ca/solarenergydesignlab/projects/multi-storey-residential-building-design (accessed May 27, 2020).

[42] X. Li, J. Peng, N. Li, Y. Wu, Y. Fang, T. Li, Optimal design of photovoltaic shading systems for multi-story buildings, J. Clean. Prod. 220 (2019) 1024-1038. doi:10.1016/j.jclepro.2019.01.246.

[43] Panasonic, HIT Photovoltaic module, (2017).

[44] Microgeneration Certification Scheme, Guide to the Installation of Photovoltaic Systems, London, 2012.

[45] European Commission, Photovoltaic geographical information system, (2019). https://re.jrc.ec.europa.eu/pvg_tools/en/tools.html (accessed September 26, 2019).

[46] S. Anuphappharadorn, S. Sukchai, C. Sirisamphanwong, N. Ketjoy, Comparison the economic analysis of the battery between lithium-ion and lead-acid in PV stand-alone application, Energy Procedia. 56 (2014) 352-358. doi:10.1016/j.egypro.2014.07.167.

[47] L. Goldie-Scot, A Behind the Scenes Take on Lithium-ion Battery Prices, Bloom. NEF. (2019).

[48] A. Jaiswal, Lithium-ion battery based renewable energy solution for off-grid electricity: A techno-economic analysis, Renew. Sustain. Energy Rev. 72 (2017) 922-934. doi:10.1016/j.rser.2017.01.049.

[49] Energy Saving Trust, Energy Storage, (2020). https://energysavingtrust.org.uk/renewableenergy/energy-storage (accessed October 3, 2020).

[50] BEIS, The Future for Small-Scale Low-Carbon Generation - A consultation on a Smart Export Guarantee, London, 2019.

[51] SSE, Gas and electricity tariffs, (2018). https://sse.co.uk/energy\#q1 (accessed August 20, 2018).

[52] Ofgem, Feed-In Tariff (FIT) rates, (2018). https://www.ofgem.gov.uk/environmentalprogrammes/fit/fit-tariff-rates (accessed July 1, 2018).

[53] F.J. Hay, Solar Electric Investment Analysis, Lincoln, 2016.

[54] Central Bedfordshire Council, Shaping where you live 2035: Central Bedforshire Pre-submission Local Plan 2015-2035, 2018.

[55] NHBC, NHBC new home statistics for England, (2018). http://www.nhbc.co.uk/.

[56] DECC, Household Electricity Survey: 24 hour profile chooser, London, 2013.

[57] DECC, Spreadsheet tools for users, WWW.GOV.UK. (2014). https://www.gov.uk/government/publications/spreadsheet-tools-for-users (accessed June 15, 2018).

[58] NHBC Foundation, Futurology The new home in 2050, Milton Keynes, 2018.

[59] Powervault, Technical Specification, (2017). https://www.powervault.co.uk/technical/technicalspecifications/ (accessed August 10, 2019). 
[60] LG Chem, Product Info: RESU 10, (2019). https://www.lgessbattery.com/eu/main/main.lg (accessed September 27, 2020).

[61] Powervault, Powervault 3: An intelligent energy storage for the smart home, (2018).

[62] Naked Solar Ltd., Compare Solar Batteries, (2020). https://nakedsolar.co.uk/storage/ (accessed September 26, 2020).

[63] F. Cucchiella, I. D'Adamo, M. Gastaldi, V. Stornelli, Solar photovoltaic panels combined with energy storage in a residential building: An economic analysis, Sustainability. 10 (2018). doi:10.3390/su10093117.

[64] W. Kuihua, N. Xinsheng, W. Jian, W. Kuizhong, J. Shanjie, Electric Vehicle Load Characteristic Analysis and Impact of Regional Power Grid, (2012) 257-261.

[65] A.J. Pimm, T.T. Cockerill, P.G. Taylor, Time-of-use and time-of-export tari ff s for home batteries: E ff ects on low voltage distribution networks, 18 (2018) 447-458. doi:10.1016/j.est.2018.06.008.

[66] M. Chediak, P. Gopal, B. Eckhouse, California Becomes First State to Order Solar on New Homes, Bloomber. (2018).

[67] A. Nottrott, J. Kleissl, B. Washom, Energy dispatch schedule optimization and cost benefit analysis for grid-connected, photovoltaic-battery storage systems, Renew. Energy. 55 (2013) 230-232.

[68] Ofgem, State of the Energy Market, London, 2018.

[69] R. Yao, K. Steemers, A method of formulating energy load profile for domestic buildings in the UK, Energy Build. 37 (2005) 663-671. doi:10.1016/j.enbuild.2004.09.007.

[70] C. Demski, C. Butler, K. a. Parkhill, A. Spence, N.F. Pidgeon, Public values for energy system change, Glob. Environ. Chang. 34 (2015) 59-69. doi:10.1016/j.gloenvcha.2015.06.014.

[71] N. Balta-Ozkan, T. Watson, P.M. Connor, C. Axon, L. Whitmarsh, R. Davidson, A. Spence, P. Baker, D. Xenias, L. Cipcigan, G. Taylor, Scenarios for the Development of Smart Grids in the UK - Synthesis Report, London, 2014. 
$2021-01-14$

\section{Optimising renewable energy integration in new housing developments with low carbon technologies}

\section{Gil, Gemma Oliver}

\section{Elsevier}

Gil GO, Chowdhury JI, Balta-Ozkan N, et al., (2021) Optimising renewable energy integration in new housing developments with low carbon technologies. Renewable Energy, Volume 169, May 2021, pp. 527-540

https://doi.org/10.1016/j.renene.2021.01.059

Downloaded from Cranfield Library Services E-Repository 